\title{
Promotores de permeação para a liberação transdérmica de fármacos:uma nova aplicação para as ciclodextrinas
}

\author{
Maria Rita Fernandes Morais Martins e Francisco Veiga* \\ Laboratório de Tecnologia Farmacêutica, Faculdade de Farmácia, Universidade de Coimbra, Portugal
}

*Correspondência:

F. Veiga

Faculdade de Farmácia de Coimbra

Rua do Norte, 3000

Coimbra (Portugal)

E-mail: fveiga@ci.uc.pt
No presente trabalho é feita uma breve revisão sobre promotores de permeação cutânea, descrevendo-se os seus mecanismos de ação e alguns exemplos. Abordam-se as vias de permeação de fármacos através da pele e liberação transdérmica. São também focadas as ciclodextrinas e seus derivados, a sua estrutura e propriedades físico-químicas, formação de complexos de inclusão e o seu papel como excipientes em sistemas transdérmicos. As ciclodextrinas constituem um grupo de excipientes que têm um papel de grande importância em formulação farmacêutica. Uma das mais extraordinárias propriedades destas moléculas é a sua capacidade de incrementar a liberação de fármacos através da pele sem, no entanto, afetar a sua função barreira.
Unitermos:

- Ciclodextrinas

- Promotores de permeação

- Liberação transdérmica

\section{INTRODUÇÃO}

O desenvolvimento de sistemas transdérmicos tem suscitado interesse crescente nas últimas décadas, uma vez que alguns fármacos foram desenvolvidos com sucesso, utilizando esta via, quer direcionados para uma ação local, quer para uma ação sistêmica (Flynn, 1990).

A eficácia clínica de um fármaco aplicado por via tópica depende, não só das suas propriedades farmacológicas, mas também da sua disponibilidade no local de ação (Loftsson, Olafsson,1998e).

A maioria dos fármacos que são utilizados no tratamento de problemas dermatológicos tem como local de ação os tecidos mais profundos da pele. Assim, o fármaco necessita permear o estrato córneo para chegar ao seu local de ação. Desse modo, a utilização clínica de fármacos por esta via está limitada pela capacidade destes ultrapassarem a barreira da pele. Por exemplo, a baixa eficácia tópica do aciclovir (análogo do nucleosídico purínico sintético, 9-[(2-hidroxi-etoxil)metil]guanina) pode ser atribuída à inadequada permeação deste fármaco antiviral através do estrato córneo até à camada basal da epiderme, isto é, o local das lesões virais. Esta impermeabilidade da pele devido ao estrato córneo afeta também os sistemas transdérmicos desenvolvidos para uma ação sistêmica, podendo causar variações individuais e imprevisíveis da liberação do fármaco a partir de sistemas transdérmicos de, por exemplo, nitroglicerina e estrogênios, entre outros.

A promoção de permeação de fármacos através da pele pode ter os seguintes resultados (Matsuda, Arima, 1999):

1. melhoramento da liberação do fármaco a partir de preparações farmacêuticas transdérmicas;

2. aumento do fluxo de fármaco através da pele ou retenção de fármaco nesta;

3. aumento da liberação localizada, tópica ou dos tecidos alvo através da pele;

4. combinação de 1,2 e 3.

Com o objetivo de, por um lado, ultrapassar os problemas devidos à impermeabilidade da pele e à variabilidade biológica e, por outro, de aumentar o número de fármacos candidatos ao desenvolvimento de medicamentos transdérmicos, vários métodos para remover reversivelmente a resistência desta barreira da pele têm sido in- 
vestigados, entre os quais, a utilização de promotores de permeação.

Outros métodos para aumentar a liberação de fármacos na pele baseiam-se na modificação físico-química de fármacos com capacidade de permeação fraca em pró-fármacos que permeiem a pele com facilidade (Bonina et al., 1991), o uso de tensoativos, lipossomas e pares iônicos, ou, mais recentemente, métodos elétricos, tais como a eletroporação e iontoforese, a aplicação de ultrasom (a sonoforese) e a terapia gênica (Wise, 2000).

Recentemente, novo grupo de excipientes foi introduzido nas formulações transdérmicas: as ciclodextrinas. Uma das mais extraordinárias propriedades das ciclodextrinas é a sua capacidade de incrementar a liberação de fármacos através da pele sem, no entanto, afetar a sua função barreira.

Ao longo deste trabalho é feita revisão dos promotores de permeação transdérmicos, das ciclodextrinas e seus derivados. Em seguida, são apresentados alguns exemplos de como as ciclodextrinas podem contribuir para a promoção da absorção transdérmica de fármacos.

\section{LIBERAÇÃO TRANSDÉRMICA}

A liberação transdérmica de fármacos pode ter como finalidade ação local ou sistêmica. Os objetivos desta última são: evitar administrações repetidas, ter liberação prolongada e manter as concentrações plasmáticas constantes.

As vantagens da via transdérmica de administração de fármacos são: diminuir as variações plasmáticas de fármaco; diminuir a freqüência de administração; anular a variabilidade da absorção oral; anular o metabolismo présistémico; possibilidade imediata de interromper a administração e constituir-se em boa alternativa à via intravenosa.

A função barreira do estrato córneo, o intervalo de tempo entre a administração e o alcançar de concentração terapêutica (lag-time), a possibilidade de irritação local e a possibilidade de desencadear tolerância e/ou resistência constituem, no entanto, em desvantagens desta via de administração.

Os fármacos que são bons candidatos ao desenvolvimento por esta via de administração são muito potentes, não-irritantes, com extensa metabolização hepática, com tempos de meia-vida curtos, que não sofrem metabolismo na pele, que não induzem tolerância e que têm bons coeficientes de partição.

\section{VIAS DE PERMEAÇÃO DO FÁRMACO}

Os apêndices da pele apenas constituem $0,1 \%$ da superfície desta pelo que se estima ser a via trans- epidérmica a principal via de permeação de fármacos (Suhonen et al., 1999). Assim, a absorção percutânea via trans-epidérmica envolve a difusão através do estrato córneo, das células viáveis da epiderme e, finalmente, das camadas superiores da derme até à microcirculação. O passo determinante da absorção cutânea é a permeação através do estrato córneo. As proteínas desta camada constituem uma camada descontínua, enquanto que a fase lipídica é contínua. Teoricamente, existem, então, duas vias potenciais de passagem: a transcelular e a intercelular, tal como se pode ver na Figura 1.

Contudo, em ambas as vias de permeação a estrutura do estrato córneo obriga o fármaco a se difundir através das bicamadas lipídicas intercelulares.

Estudos experimentais indicam que a permeação da maioria dos compostos através da camada córnea está dependente, quer da sua lipofilicidade quer do seu tamanho molecular (Guy e Hadgraft, 1992; Boddé et al., 1991).

\section{PROMOÇÃO DE PERMEAÇÃO QUÍMICA DE FÁRMACOS ATRAVÉS DA PELE}

Os promotores de permeação são compostos químicos, por si só, farmacologicamente inativos, mas que podem permear ou interagir com constituintes do estrato córneo, quando incorporados numa formulação transdérmica e, deste modo, diminuir a resistência da pele à difusão do fármaco (Walters, 1989; Barry, 1987). Um promotor de permeação deve incrementar a atividade termodinâmica do fármaco, resultando daí aumento do seu fluxo.

Um modo de promover a permeação de fármacos através da pele é a alteração reversível da sua função barreira. A ação dos promotores "convencionais" (tais como, álcool e ácidos graxos) na bicamada lipídica deve envolver interações nos dois locais indicados na Figura 2, isto é, nos grupos das cabeças polares dos lipídios e nas cadeias hidrofóbicas da bicamada. Assim, resulta o incremento da fluidez da membrana.

O promotor de permeação ideal será aquele que apresenta as seguintes caraterísticas: farmacologicamente inerte, não-tóxico, de ação imediata, não-irritante, nãoalérgico, de ação reversível, química e fisicamente compatível com o fármaco e excipientes, aceitável cosmeticamente, inodoro, insípido, incolor, acessível e com boas propriedades solventes (Hadgraft, 1999; Sinha, Kaur, 2000).

Considerando uma representação ideal da pele, podem ser adotadas diferentes estratégias para otimizar o desenvolvimento de transdérmicos, tal como está esquematizado na Figura 3, e será abordado seguidamente. 


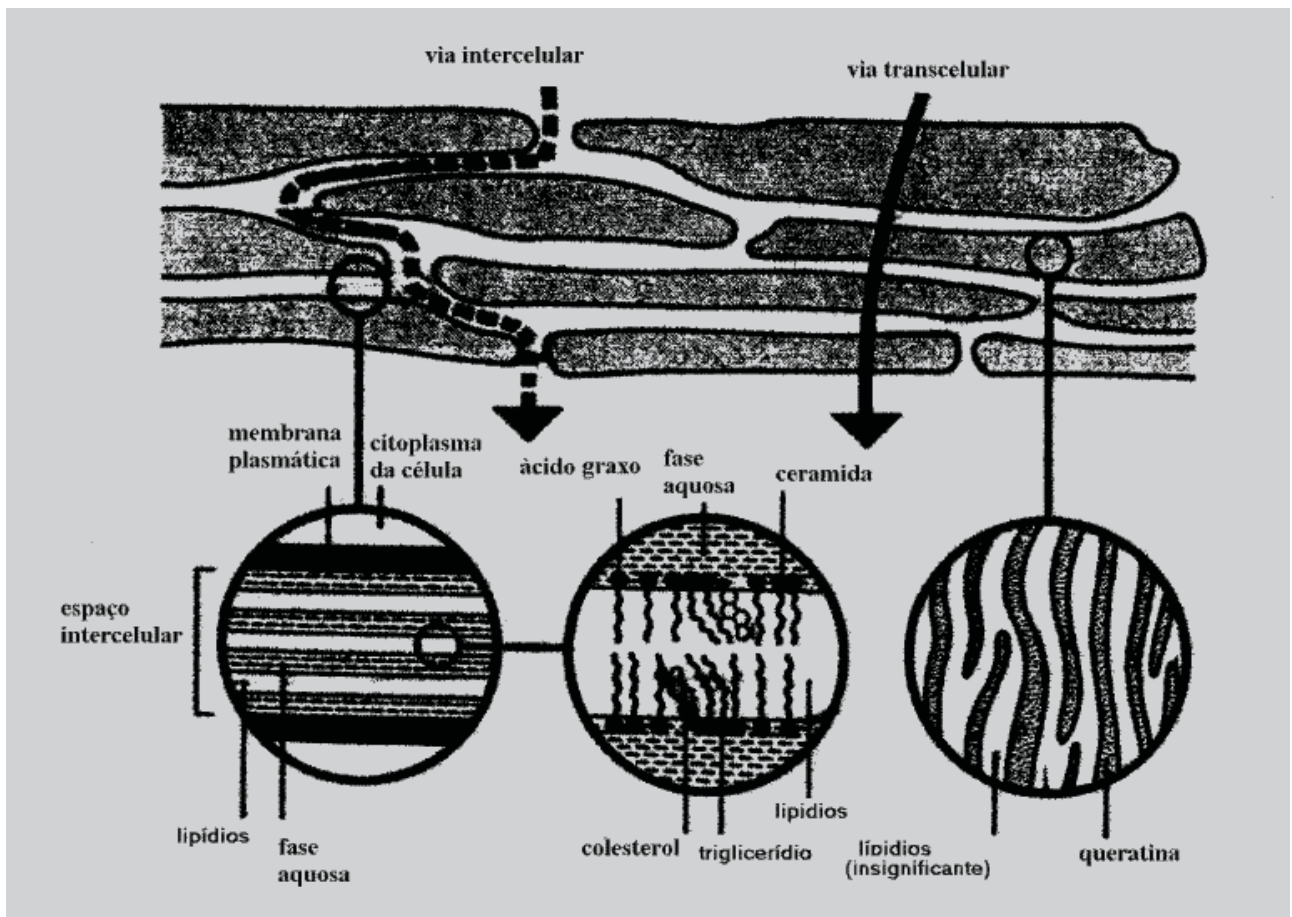

FIGURA 1 - Esquema que representa as vias de permeação do fármaco através do estrato córneo, isto é, através dos corneócitos e da matriz lipídica intercelular - via transcelular, e via da matriz lipídica entre os corneócitos - via intercelular (adaptado de Suhonen et al., 1999).

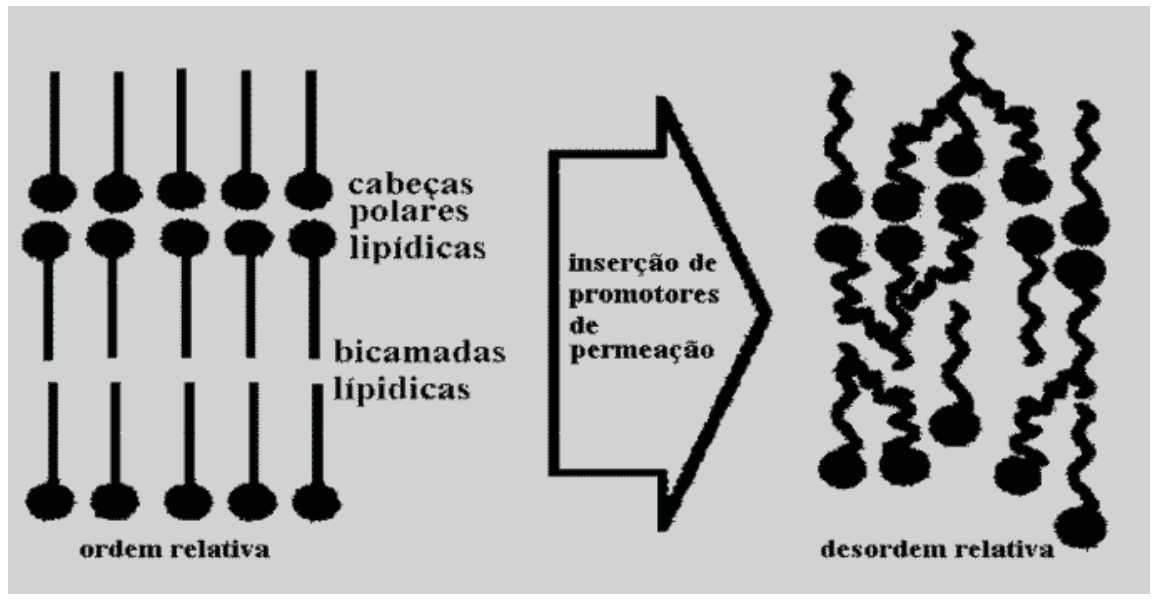

FIGURA 2 - Esquema que representa os locais de ação dos promotores de permeação nos lipídios intercelulares do estrato córneo, isto é, nos grupos polares das cabeças lipídicas e/ou nas cadeias hidrofóbicas da bicamada. Representa-se a mudança de ordenamento (como estado normal dos lipídios intercelulares e que são responsáveis pela função barreira) para desordem relativa provocada por um promotor de permeação (adaptado de Suhonen et al.,1999).

\section{Efeitos de Formulação}

A velocidade de liberação de um fármaco à superfície da pele pode ser importante particularmente no caso de sistemas transdérmicos, nos quais é necessário o contro- le da velocidade. A difusão através da matriz polimérica do sistema de liberação deve ser significativamente mais lenta do que a velocidade de passagem através do estrato córneo (Hadgraft, 1999).

Com o objetivo de aumentar a absorção é possível 


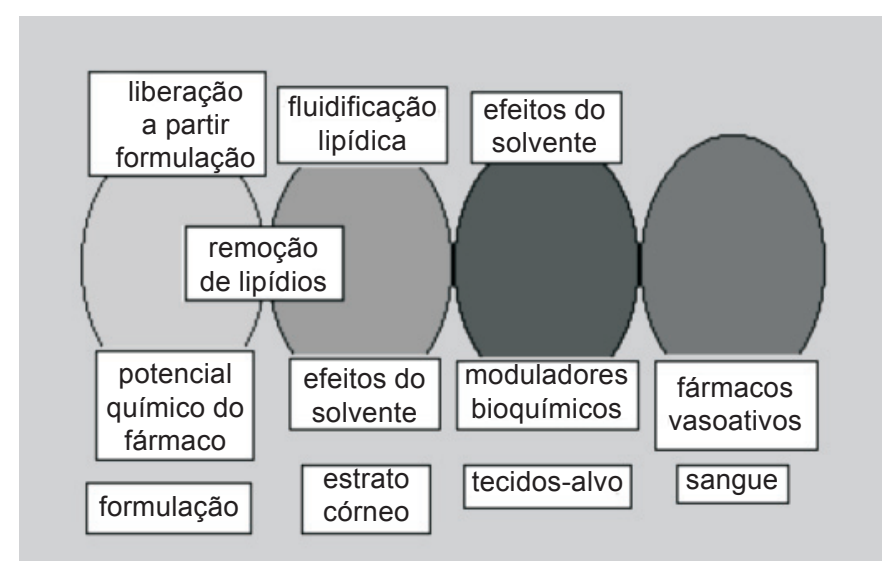

FIGURA 3 - Representação esquemática da pele e das várias vias estratégicas de promoção de permeação que podem ser consideradas.

usar soluções supersaturadas, que têm potenciais químicos maiores do que as soluções saturadas. Parece haver um incremento quase linear do fluxo de fármaco com o grau de supersaturação (Hadgraft, 1999). No entanto, estas soluções supersaturadas são necessariamente mais instáveis, pois durante o seu armazenamento é possível a ocorrência de fenômenos de cristalização, que, inevitavelmente, alteram a eficácia do respectivo sistema transdérmico. Este tipo de soluções pode ser estabilizado por meio da adição de polímeros solúveis em água, mas, habitualmente, apenas durante períodos limitados de tempo (Loftsson, 1998a).

É comum pensar-se que um aumento da concentração do fármaco aplicado na pele vai incrementar o seu fluxo, o que é um conceito errado. A força condutora da difusão através da pele é o gradiente químico potencial (Hadgraft, 1999). Twist e Zatz (1988) demonstraram o significado deste fato com um estudo de difusão de parabenos através de uma membrana de silicone. Utilizaram-se soluções saturadas de fármaco em 11 solventes diferentes. Devido às diferentes solubilidades a concentração do fármaco variava em duas ordens de magnitude. Apesar disso, o fluxo do permeante foi o mesmo para os diferentes solventes testados. Tal fato era esperado, uma vez que nenhum dos solventes alterou as propriedades da membrana.

Alguns solventes podem remover os lipídios do estrato córneo. A função barreira é reduzida quando os lipídios são alterados desta forma, apesar deste efeito ser reversível. Alguns produtos tópicos e sistêmicos contêm elevadas concentrações de solventes, tais como o álcool, que pode alterar o conteúdo lipídico da pele (Bommannan et al., 1991).

\section{Efeitos no estrato córneo}

A verificação da primeira lei de Fick da difusão mostra que efeito máximo pode ser obtido se o excipiente da formulação permear o estrato córneo. Este é intercalado na sua estrutura lipídica, provoca destruição do seu empacotamento, maior fluidez e, portanto, pode aumentar o coeficiente de difusão do fármaco. Este efeito foi demonstrado por DSC (calorimetria diferencial de varredura) com medições dos efeitos de transições de temperatura (Cornwell et al., 1996), estudos ESR (ressonância magnética de spin) (Gay et al., 1989), investigações FTIR (espetroscopia de infravermelho com transformadas de Fourrier) (Golden et al., 1986) e espetroscopia de fluorescência (Barry et al., 1992).

A caraterística molecular típica de um promotor de permeação que destabiliza os lípidios da pele é uma cabeça polar com uma longa cadeia alquílica $\left(\mathrm{C}_{10}\right.$ a $\mathrm{C}_{14}$ é o ideal $)$ (Bouwstra et al., 1989). Compostos como tensoativo nãoiônicos têm algumas propriedades e o Brij 36T mostrou-se como promotor efetivo (Walthers et al., 1988). O ácido oléico atua, também, como desestabilizante dos lipídios da pele formando poros (Ongpipattanakul et al., 1991).

Um dos problemas desta propriedade de desestabilização lipídica é que este tipo de moléculas tende a tem propriedades irritantes. Quanto mais se conhece acerca da atividade estrutural dos promotores e da irritação cutânea mais perto se está de desenhar moléculas com propriedades ideais (Hadgraft, 1999).

Uma segunda forma dos excipientes poderem modificar a permeabilidade da pele é alterando os parâmetros de solubilidade desta relativamente ao permeante. A solubilidade do permeante na camada externa da pele é aumentada e tem como resultado o aumento do fluxo. Os compostos que atuam deste modo são o propilenoglicol, etanol e $N$-metilpirrolidona. A $1^{\text {a }}$ lei de Fick da difusão demonstra que estratégias de promoção de permeação incluindo efeitos na difusão $\left(D_{B}\right)$, ou efeitos na solubilidade, têm um efeito multiplicativo. Demonstrou-se que promotores de permeação como a azona, incrementam o coeficiente de difusão, $\mathrm{D}_{\mathrm{B}}$, do cianofenol com um fator de 3 . É também conseguido um efeito semelhante, quando a supersaturação é combinada com um "fluidificador lipídico" (Hadgraft, 1999).

\section{Efeitos nos tecidos alvo}

Alguns permeantes pouco lipofilicos podem ter alguns problemas de solubilidade nos tecidos alvo. A presença local de solventes tais como o propilenoglicol pode ser vantajosa. 
As regiões mais profundas da pele são bioquimicamente muito ativas e tem sistemas enzimáticos responsáveis pela síntese de lipídios, que mantêm a função barreira do estrato córneo. A utilização de ácidos graxos e inibidores da síntese de colesterol tem sido apresentada como promotora de permeabilidade na pele de rato. Da combinação destes dois inibidores resulta efeito sinérgico (Tsai et al., 1996).

\section{Fármacos vasoativos}

Os fármacos vasoativos podem ter papel importante na remoção local do permeante. Se forem utilizados fármacos vasoconstritores, a taxa de remoção será reduzida, o que pode levar a aumento das concentrações locais do permeante nos tecidos viáveis da epiderme e da derme.

\section{TRANSPORTE DE SUBSTÂNCIAS ATRAVÉS DO ESTRATO CÓRNEO}

\section{Influência e concordância com a 1ª lei de FICK}

Desde que o estrato córneo foi considerado barreira permeável, a permeação de fármacos através desta camada da pele pode ser descrita pela primeira lei de Fick (1) (Bach et al., 1998).

$$
\begin{aligned}
& -\frac{d c_{V}}{d t}=k_{p} \times c_{V}=\frac{D_{B} \times P C_{B / V}}{l} \times \frac{A}{V_{V}} \times c_{V} \\
& J=P_{B} \times c_{V}=\frac{D_{B} \times P C_{B / V}}{l} \times c_{V} \\
& P C_{B / V}=\frac{c_{S B}}{c_{S V}} \\
& J=\frac{D_{B} \times c_{S B}}{l} \times \frac{c_{V}}{c_{S V}}
\end{aligned}
$$

Em que:

$\mathbf{c}_{\mathbf{v}}$ - concentração do fármaco no veículo

$-\mathbf{d c} \mathbf{c}_{\mathbf{v}} / \mathbf{d t}$ - velocidade a que a concentração de fármaco decresce no veículo

$\mathbf{K}_{\mathbf{p}-}$ constante de permeação

$\mathbf{D}_{\mathbf{B}-}$ coeficiente de difusão do fármaco

$\mathbf{P C}_{\mathbf{B} / \mathbf{V}}$ - coeficiente de partição do fármaco entre o estrato córneo e o veículo

A - área de aplicação

$\mathbf{V}_{\mathbf{v}}$ - volume de veículo

$\mathbf{P}_{\mathrm{B}}$ - permeabilidade do estrato córneo

$\mathbf{c}_{\mathrm{SB}}-$ solubilidade do fármaco no estrato córneo

$\mathbf{c}_{\mathrm{sv}}$ - solubilidade do fármaco no veículo

$\mathbf{J}$ - fluxo de fármaco

l - espessura da camada córnea
O fluxo de fármaco, J, representa a quantidade de fármaco que permeia por unidade de tempo e por unidade de área. A velocidade de permeação e o fluxo são diretamente proporcionais à permeabilidade do fármaco na barreira $\left(\mathrm{P}_{\mathrm{B}}\right)$.

Se o coeficiente de partição $\left(\mathrm{PC}_{\mathrm{B} / \mathrm{V}}\right)$ na equação (2) for substituído pela equação (3), obtemos a equação (4).

Assim, o fluxo de fármaco através da pele, J, aumenta com:

- o incremento do coeficiente de difusão do fármaco na barreira $\left(\mathrm{D}_{\mathrm{B}}\right)$ e com a solubilidade do fármaco na barreira $\left(\mathrm{c}_{\mathrm{SB}}\right)$;

- o aumento de concentração de fármaco no veículo $\left(\mathrm{c}_{\mathrm{v}}\right)$ ou com o decréscimo da sua solubilidade no veículo $\left(\mathrm{c}_{\mathrm{SV}}\right)$.

Nenhum promotor de permeação por si só possui todas as propriedades requeridas. Contudo, muitos promotores exibem vários destes atributos e vêm sendo testados em clínicas ou laboratórios de investigação. Muitos investigadores dedicam-se ao estudo da permeação transdérmica usando vários promotores para diversos fármacos. Alguns importantes promotores de permeação utilizados na liberação de fármacos transdérmicos são apresentados seguidamente.

\section{Terpenos, Terpenóides e Óleos Essenciais}

Terpenos e terpenóides são normalmente os constituintes dos óleos voláteis. A sua estrutura química consiste em grupos isopreno $\left(\mathrm{C}_{5} \mathrm{H}_{8}\right)$ repetidos e é classificada de acordo com o número de grupos isopreno.

Observou-se que o L-mentol (presente em elevada quantidade no óleo de hortelã pimenta) aumenta a absorção cutânea da testosterona pela formação de mistura eutética com o fármaco, reduzindo o seu ponto de fusão drasticamente de $153,7{ }^{\circ} \mathrm{C}$ para $39,9^{\circ} \mathrm{C}$ como foi observado por DSC, o que aumenta a sua solubilidade e, conseqüentemente, a sua absorção. Em estudos adicionais observou-se que o mentol também aumenta a absorção de ceramidas e oleato de colesteril. O mentol afeta a permeação cutânea por meio de um mecanismo duplo: pela formação de mistura eutética com o composto permeante, aumentando deste modo a sua solubilidade, e pela alteração da propriedade barreira do estrato córneo. O mentol distribui-se preferencialmente nos espaços intercelulares do estrato córneo e causa, possivelmente, destabilização reversível das camadas lipídicas, aumentando, assim, a permeação dos fármacos (Kaplun, Frischoff, 1997).

O efeito de três óleos essenciais (eucalipto, hortelã pimenta e terpentina) na permeação da fluoruracila (5-FU) 
foi estudado usando pele de rato removida cirurgicamente. Apesar dos três óleos aumentarem a permeação do fármaco, o seu efeito foi menor que o da azona. O óleo, de eucalipto foi o que se mostrou mais ativo, causando aumento da permeação de fármaco em 60 vezes, enquanto que o de hortelã pimenta e o de terpentina mostraram aumentos de 48 e 28 vezes, respectivamente. O modo de ação destes três promotores pode ser devido a processo combinado de partição e difusão, sendo este último dominante.

A permeação de quatro fármacos modelo (cloridrato de nicardipino, hidrocortisona, carbamazepina e tamoxifeno) foi testada com quatro terpenos (fenchona, timol, D-limoneno e nerolidol) em pele de rato em pêlo. Verificou-se que a lipofilicidade dos terpenos tem efeito significativo na permeação dos fármacos testados. O terpeno mais lipofílico, o nerolidol, foi o que demonstrou efeito de promoção mais efetivo na promoção, seguido pelo limoneno e pelo timol. Os terpenos foram mais efetivos na promoção de permeação para o fármaco mais lipofílico, o cloridrato de nicardipino (El-Kattan et al., 2001)

\section{Pirrolidonas}

As pirrolidonas e seus derivados têm grande potencial como promotores de permeação transdérmicos. A mais comum, a $N$-metil-2-pirrolidona (NMP), tem sido amplamente usada para aumentar a absorção pela pele de muitos fármacos, como por exemplo insulina, ibuprofeno e flurbiprofeno. O fluxo do fármaco antiinflamatório ibuprofeno foi incrementado em 16 vezes e o de flurbiprofeno em três vezes, com o uso de NMP, através da pele de cadáver (Sinha e Kaur, 2000).

Em geral, a 2-pirrolidona promove a permeação transdérmica da cafeína através da via polar da pele (poros), pelo aumento da sua difusibilidade, e reduz a passagem através da via não polar pelo decréscimo da sua difusibilidade, e do seu coeficiente de partição nesta via. Um dos seus derivados, a $N$-dodecil-2-pirrolidona mostrou que aumenta o coeficiente de permeação do metilparabeno hidrofílico em aproximadamente sete vezes, enquanto que o do butilparabeno é reduzido. A perturbação da bicamada lipídica do estrato córneo parece estar relacionada com o aumento da absorção do parabeno hidrofílico. Ésteres de ácidos graxos de $N$-(2-hidroxietil)2 -pirrolidona (HEP) duplicaram a permeação da hidrocortisona através da pele de rato. As ligações éster foram clivadas por enzimas hidrolíticas do plasma e homogeneizados de pele (Lambert et al., 1993).

A azona (1-dodecilazacicloeptano-2-ona) (Figura 4) constitui uma das maiores classes de promotores de permeação percutâneos. A escolha do solvente tem sido considerada como muito importante quando se utiliza a azona como promotor de permeação. Quando a azona foi utilizada em combinação com o propilenoglicol (PG), o fluxo de metotrexato (Chatterjee et al., 1997) e piroxicam aumentou significativamente.

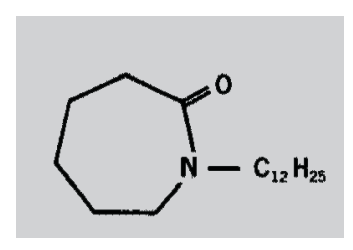

FIGURA 4 - Estrutura química da azona.

A estrutura química da azona é considerada híbrida de dois promotores de permeação - pirrolidona e decilmetilsulfóxido. $\mathrm{O}$ anel polar e a longa cadeia alquilíca presentes na posição 1 são necessários para a sua ação.

Dois compostos quimicamente similares à azona, a capsaicina (8-metil $\mathrm{N}$-vanilil-6-nonenamida, $\mathrm{C}_{18} \mathrm{H}_{27} \mathrm{NO}_{3}$ ) e nonivamida ( $N$-nonanoíl vanililamida, $\mathrm{C}_{17} \mathrm{H}_{27} \mathrm{NO}_{3}$ ) demostraram promover a permeação da indometacina através da pele de rato sem pêlo. Pensa-se que o seu mecanismo de ação é semelhante ao da azona devido às suas semelhanças estruturais e tamanho molecular. A azona atua intercalando-se nas matrizes de ceramidas levando à destabilização da camada córnea e, conseqüentemente, à diminuição da resistência à difusão desta camada (Fang et al., 2001).

Foi realizado um estudo em que se examinaram duas séries de derivados da 3-(2-oxo-1-pirrolidona) hexaidro- $1 H$-azepina-2-ona, uma com cadeias alquílicas e outra com cadeias alquil éster. $\mathrm{O}$ fármaco permeante através de pele de rato sem pêlo foi a hidrocortisona. Verificou-se que os promotores da primeira série são mais ativos que a azona e apresentam capacidade de promoção de permeação mais elevada que os da segunda série (ElKattan, et al., 2001)

A azona é menos efetiva que o ácido oléico no aumento da permeação transdérmica de aminoácidos através da pele de rato sem pêlos. No entanto, caso da insulina o aumento é quase duplo do produzido pelo dodecil-Lpiroglutamato. Comparada com os terpenos, a azona é o promotor de permeação mais efetivo para heparinas de baixo peso molecular através da pele humana. O poder de aumento de permeação dos promotores decaiu na seguinte ordem de grandeza laurocapram $>$ nerolidol $>$ eucaliptol (Xiong et al., 1996). 


\section{Ácidos Graxos e Ésteres}

Amplo número de ácidos graxos e os seus ésteres tem sido utilizado como promotores de permeação. Uma tendência geral que se tem observado é que os ácidos graxos insaturados são mais efetivos na promoção da absorção percutânea de fármacos que os seus homólogos saturados. Chi et al. (1995) referiram-se a incremento de 6,5 vezes a 17,5 vezes na velocidade de permeação do flurbiprofeno através da pele de rato, pelos ácidos graxos insaturados, enquanto que nenhum aumento significativo foi observado utilizando ácidos graxos saturados.

A adição de ácido oléico a um sistema de cosolventes etanol:água (50:50) promoveu marcadamente a permeação de zalcitabina, didanosina e zidovudina através da pele de rato com pêlo, enquanto que a sua adição a etanol:tricaprilina (TCP) $(50: 50)$ não promoveu a permeação através da pele de rato sem pêlo. Estes resultados sugeriram que o viscoso TCP reduziu a atividade termodinâmica do ácido oléico (Kim e Chien, 1996) e que o ácido oléico foi o promotor de permeação mais eficiente para o piroxicam seguido do ácido linoléico e que o oleato de sódio foi promotor de permeação melhor que o oleato de oleíla, quando testado com os fármacos indometacina e uréia (Ogiso et al., 1995).

O ácido oléico aumentou marcadamente o coeficiente de permeação da melatonina através da pele de rato sem pêlo em mais de 950 vezes comparativamente ao obtido com o propilenoglicol usado somente como veículo. Assim, demonstrou-se que o ácido oléico utilizado num veículo adequado é um promotor de permeação da melatonina mais eficaz do que com os veículos etanol, polietilenoglicol, propilenoglicol e respectivas misturas binárias (Oh et al., 2001; Garrison et al., 1994).

O extrato de ácido graxo do óleo de fígado de bacalhau tem-se demonstrado tão capaz de ser promotor de permeação como o ácido oléico. O promotor de permeação transdérmico mais efetivo foi o ácido palmitoléico, que propriciou aumento de 640 vezes no fluxo de hidrocortisona através da pele de rato sem pêlo. A incorporação de óleo de fígado de bacalhau puro num veículo com PG não aumentou a permeação da hidrocortisona, sugerindo que os ácidos graxos insaturados têm que estar na sua forma livre para serem capazes de atuar como promotores de permeação. Um pré-tratamento da pele abdominal de coelho durante 1 hora com $10 \%$ de ácido oléico em PG aumentou em grande medida a absorção do piroxicam a partir de um gel.

Estudo com ácido laurico e cáprico, usando como fármaco o propranolol levou a concluir que estes formam misturas binárias eutéticas com o fármaco. $\mathrm{O}$ efeito no aumento do fluxo do propranolol através da pele humana pode ser explicado pelas caraterísticas de fusão dos compostos de adição formados (Stott et al., 2001).

Não está identificado um mecanismo único de promoção de permeação para os ácidos graxos e parece que os efeitos de promoção de permeação são seletivos para cada fármaco e condições de administração.

\section{Sulfóxidos e Compostos Similares}

O dimetilsulfóxido (DMSO), o composto mais importante que pertence à categoria dos sulfóxidos e compostos similares, aumenta a permeação transdérmica de uma vasta quantidade de fármacos, como os $\beta$-bloqueantes, cloridrato de efedrina e cloridrato de papaverina. O DMSO também aumenta a liberação da azapropazona a partir de cremes. Estudos FTIR revelaram que o DMSO altera a queratina do estrato córneo, de conformação em $\alpha$ hélice para conformação em camada- $\beta$. Para concentrações maiores que $60 \%(\mathrm{v} / \mathrm{v})$, para as quais DMSO promove o fluxo, existem evidências da sua interação com os lípidos do estrato córneo. Também produz alterações na estrutura das proteínas, mas pode também estar relacionado com alterações na organização do estrato córneo, para além de um aumento do coeficiente de partição do fármaco. Num estudo efetuado por Clancy et al. (1994) utilizando ATR-FTIR (espetroscopia por transformadas de Fourrier com reflexão total atenuada) e DSC foi confirmado que um tratamento com DMSO (da pele humana) provoca extração extensiva dos lipídios e desnaturação das proteínas do extrato córneo. O DMSO mostrou efeito promotor negligenciável na difusão do piroxicam e foi menos efetivo que o cloreto de laurila no aumento do fluxo do maleato de timolol através da pele humana.

Vários compostos da categoria das $N, N$-dimetilamidas possuem também capacidade de promoção de permeação sendo estruturalmente relacionadas com os sulfóxidos. A $N, N$-dimetilformamida promove a absorção através da via polar de permeação por incremento, quer do coeficiente de partição, quer do coeficiente de difusão do fármaco. Este promotor de permeação aumenta o coeficiente de permeação da cafeína (pele humana) e do cloridrato de efedrina (pele de rato e epiderme humana). A dimetilacetamida (DMA) promove a permeação da indometacina a partir de cremes e pomadas, em ratos. A $\mathrm{N}, \mathrm{N}$-dimetiloctanamida e $\mathrm{N}, \mathrm{N}$-dietildecanamida monstraram-se promotores de permeação efetivos do antiinflamatório não-esteróide ibuprofeno e naproxeno a partir de um veículo aquoso a 50\% de PG através da pele de rato (Irwin et al., 1990).

O dimetilsulfóxido (DMSO) e a dimetilformamida 
(DMF) foram estudados na promoção de permeação do cloridrato de prazocina através de pele de rato sem pêlo. Verificou-se que a permeação deste fármaco experimentou aumento significativo com DMSO, mas não com DMF (Reddy, Ghosb, 2001).

\section{Álcoois, Glicóis e Glicerídios}

O etanol é o álcool mais utilizado como promotor de permeação transdérmico. Este aumenta a permeação do cetoprofeno a partir de uma formulação gel em spray e de salicilato de trietanolamina a partir de emulsão de base hidrofílica (Babar et al., 1991). Também atua como veículo para o mentol no aumento da penetração do metilparabeno (Kitagawa et al., 1997; Kobayashi et al., 1994).

O etanol em combinação com o TCP e com água foi usado em dois sistemas de co-solventes para os fármacos: zalcitabina, didanosina, zidovudina, tegafur, alclofenaco e ibuprofeno. A velocidade de permeação da zalcitabina, da didanosina e da zidovudina aumentou com o volume da fração de etanol nos dois sistemas de co-solventes, tendo atingido máximo a 50-60\% (v/v) de etanol. O fluxo de tegafur, de alclofenaco e de ibuprofeno foi maior a partir de um sistema de co-solventes etanol-água do que a partir de um sistema de TCP-etanol (Lee et al., 1993).

O etanol atua como promotor de permeação por extração de grandes quantidades de lipídios do estrato córneo. O etanol também aumenta o número de grupos sulfidrila livres da queratina das proteínas do estrato córneo. Usualmente, pré-tratamento da pele com etanol incrementa a permeação de compostos hidrofílicos, enquanto que decresce a dos hidrofóbicos (Sugibayashi et al., 1992).

O propilenoglicol (PG) promove o fluxo de heparina sódica (Bonina, Montenegro, 1992), cloridrato de verapamil e cetoprofeno, mas, em concentrações muito elevadas inibe o fluxo de cetoprofeno. A solução saturada de terpenos num sistema de co-solventes PG/água aumenta o fluxo de 5-FU, a atividade do terpeno está dependente do conteúdo de $\mathrm{PG}$ e obtém-se fluxo máximo a partir de formulações contendo $80 \%$ de PG. O PG também aumenta os coeficiente de permeação e de partição (Yamane et al., 1995). O PG, em combinação com a azona, aumenta o fluxo dos fármacos metotrexato (Chatterjee et al., 1997), piroxicam, ciclosporina A e fluoruracila (5-FU). O fluxo de estradiol aumentou dez vezes quando o PG foi utilizado em conjugação com $5 \%$ de ácido oléico. Análogos da uréia foram efetivos na promoção de permeação do 5-FU somente quando o PG foi utilizado como veículo (Williams, Barry, 1989).

O PG solubiliza a queratina do estrato córneo, ocupando os locais de ligação de hidrogênio. Quando o PG foi utilizado em combinação com a azona, grandes quantida- des de glicol entraram no tecido, o que promoveu a difusão intracelular de fármaco (Phillips, Michniak, 1995).

O 1-decanol e o álcool etílico foram estudados na promoção de permeação do atenolol através de pele de rato sem pêlo. Verificou-se que a permeação deste fármaco teve aumento significativo em ambas as soluções alcoólicas (Reddy, Ghosb, 2001).

$\mathrm{O}$ efeito de sistemas de solventes tais como água, etanol, PG e a suas combinações binárias foram estudadas em pele de rato em pêlo utilizando como fármaco a naloxona. Verificou-se que houve incremento do fluxo de fármaco, sendo o máximo obtido com a mistura de $33 \%$ de PG em etanol (Panchagnula et al., 2001).

\section{Fosfolipídios}

Derivados de fosfatidilglicerol aumentam a acumulação de bifonazol na pele e a permeação percutânea do tenoxicam e derivados da fosfatidilcolina promovem a permeação percutânea da eritromicina. Seis derivados do fosfatidilglicerol (PGE), cinco da fosfatidilcolina (PC) e dois da fosfatidiletanolamina foram estudados usando a indometacina. Os resultados sugerem que fosfolipídios contendo ácidos graxos insaturados no grupo hidrofóbico são fortes promotores de permeação na liberação cutânea de alguns fármacos aplicados topicamente (Yokomizo, Sagitani, 1996).

\section{Inibidores da Síntese Lipídica}

A camada barreira da pele (estrato córneo) consiste em mistura de colesterol, de ácidos graxos livres e de ceramidas e estas três classes de lipídios são requeridas para função barreira normal. A adição de inibidores da síntese lipídica aumenta a liberação de alguns fármacos como a lidocaína e a cafeína. Os inibidores da síntese dos ácidos graxos como o ácido 5-(tetradeciloxi)-2furancarboxílico (TOFA) e os inibidores da síntese de colesterol, tais como, fluvastatina (FLU) ou sulfato de colesterol (CS) atrasam a recuperação dos danos na barrei$\mathrm{ra}$, quando produzidos por aplicação prévia de promotores de permeação, como DMSO ou acetona. Concluiu-se que a modulação da biossíntese lipídica após a aplicação de promotores de permeação químicos convencionais provoca avanço na permeação transdérmica (Tsai et al., 1996).

\section{Derivados de Aminoácidos}

Vários derivados de aminoácidos têm sido estudados pelo seu potencial na melhoria da permeação percutânea de fármacos. A aplicação de éster metílico $N$ - 
dodecil-L-aminoácido e $n$-pentil- $N$-acetil prolinato em pele de rato sem pêlo removida cirurgicamente, uma hora antes do tratamento com o fármaco hidrocortisona, produziu aumento da permeação deste a partir de uma suspensão. $\mathrm{O} n$-pentenil- $N$-acetil prolinato também promove o fluxo de ácido benzóico através da pele de cadáver humano; não é tóxico em doses baixas, mas, em doses elevadas, produz toxicidade dependente da dose no sistema nervoso central. Os ésteres dos aminoácidos ômega tais como octil-6-aminoexanoato e decil-6-aminoexanoato aumentam a permeação transdérmica da teofilina em veículos aquosos ou oleosos, respectivamente (Sinha, Kaur, 2000).

A eficiência do promotor de permeação biodegradável isopropionato dodecil $N, N$-dimetiamino (DDAIP) foi comparada com a do acetato dodecil- $N, N$-dimetilamino (DDAA), azona e outros promotores de permeação conhecidos. O DDAIP mostrou aumento do fluxo de 5-FU dependente da dose. Além disso, o DDAIP produziu melhor promoção que a DDAA e a azona. O DDAIP incrementa o fluxo de indometacina. A ligações de hidrogênio e as interações dipolo-dipolo foram referidas na ligação do fármaco com a DDAIP (Turunen et al., 1993).

\section{Ácido Clofíbrico}

Os ésteres e as amidas do ácido clofíbrico foram estudados pelas suas propriedades de promotores de permeação usando pele de rato sem pêlo. A melhor permeação para o acetato de hidrocortisona-21 e o 17valerato de betametasona foi observada com a octil amida do ácido clofíbrico, aplicada uma hora antes de cada esteróide. Amidas análogas são, geralmente, mais efetivas que os ésteres derivados, com o mesmo comprimento de cadeia hidrocarbônica (Michiniak et al., 1993).

\section{Acetato de Dodecil-N,N-Dimetilamino}

$\mathrm{O}$ acetato de dodecil- $N, N$-dimetilamino (DDAA) aumentou a permeação transdérmica de vários fármacos como o cloridrato de propanolol e o maleato de timolol. Observou-se que este promotor foi tão eficaz como a azona, possuindo vantagem sobre esta; a irritação da pele com o DDAA desaparece num período curto de tempo, quando comparada com o da azona. O DDAA também incrementa o fluxo transdérmico de 5-FU através de pele de cobra. Além disso, a substituição de um átomo de hidrogênio do seu grupo acetato, por um grupo metila, aumenta grandemente o seu poder de permeação. $\mathrm{O}$ aumento do fluxo, através da pele de rato sem pêlo, do tetrapeptídeo hisetal pelo DDAA, foi de 1,5 vezes maior do que o conseguido com a azona. O efeito de promoção de permeação foi devido a alterações na estrutura lipídica do estrato córneo, como no caso da azona e do ácido oléico. O aumento da permeação transdérmica do sotalol pelo DDAA foi o mesmo que o produzido por iontoforese. O DDAA provoca a destabilização da bicamada lipídica do estrato córneo. A sua duração de ação é mais reduzida que a da azona e do álcool dodecílico devido à presença de grupos hidrofílicos. Então, há recuperação mais rápida da estrutura da pele e, por isso, menor potencial de irritação. $\mathrm{O}$ DDAA também exerce efeito de hidratação da pele (Sinha, Kaur, 2000).

\section{Enzimas}

Devido à importância do metabolismo da fosfatidilcolina durante a maturação da bicamada lipídica, a aplicação tópica da fosfatidilcolina dependente da enzima fosfolipase $\mathrm{C}$ produziu e aumentou o fluxo transdérmico de ácido benzóico, manitol e testosterona. Três enzimas epidérmicas (hidrolase triacilglicerol (TGH), fosfatase ácida, fosfolipase $\mathrm{A}_{2}$ ) foram também estudadas pelos seus efeitos epidérmicos. A fosfatase ácida foi ineficaz, a TGH aumentou a permeação do manitol enquanto que a fosfolipase $\mathrm{A}_{2}$ aumentou tanto o fluxo do ácido benzóico como o do manitol. O pré-tratamento da pele com papaína produziu alterações reversíveis na estrutura protéica do estrato córneo. Estas alterações resultaram em aumento de permeação de proteínas de vários pesos moleculares, tendo este efeito diminuído com o aumento do peso molecular (Patil et al., 1996).

\section{Complexos com Ciclodextrinas}

Grande número de complexos ciclodextrina/ fármaco foram produzidos e tais combinações, normalmente, aumentam a permeação dos fármacos através da pele. Por exemplo, o complexo de inclusão piroxicam com a $\beta$-ciclodextrina aumenta o fluxo do fármaco em três vezes através da pele de rato e complexo similar do clonazepam com a metil- $\beta$-ciclodextrina melhorou o seu perfil de liberação a partir do hidrogel de carbopol através de uma membrana de nitrato de celulose (Mura et al., 1992).

Em solução, as ciclodextrinas formam complexo com promotores de permeação, tais como sais de amônio quaternário, e alteram a sua concentração micelar crítica para valores mais elevados, diminuindo, desta forma, o efeito tóxico de tais promotores. A absorção transdérmica do alprostadil (AP) a partir do seu complexo com $\beta$ ciclodextrina e do complexo $O$-carboximetil- $O$-etil- $\beta$ ciclodextrina (CME- $\beta-C D)$, foram comparados através da 
pele de rato sem pêlo. A HPE-101 (1-(2-(deciltio)etil) azaciclopentano-2-ona) foi incluída como promotor de permeação em ambos os casos. O fluxo a partir do último complexo foi 10 vezes mais elevado do que o do complexo anterior. Concluiu-se que a combinação da CME-b-CD e HPE-101 aumenta a biodisponibilidade tópica do fármaco (Adachi et al., 1993).

\section{CICLODEXTRINAS}

As ciclodextrinas são oligossacarídios cíclicos formados por pelo menos 6 unidades de glicose, sendo as mais conhecidas a $\alpha$-ciclodextrina ( 6 unidades), a $\beta$ ciclodextrina ( 7 unidades) e a $\gamma$-ciclodextrina ( 8 unidades).

Apesar das ciclodextrinas naturais $(\alpha, \beta$ e $\gamma$ ciclodextrinas) serem bastante utilizadas na investigação e desenvolvimento de formulações farmacêuticas, elas apresentam algumas propriedades menos adequadas enquanto transportadores de fármacos. Esta limitação levou a que as ciclodextrinas naturais fossem quimicamente modificadas em função de diferentes objetivos (Veiga, 1996).

\section{Estrutura e propriedades físico-químicas}

As unidades de glicose que constituem as ciclodextrinas encontram-se unidas por ligações $\alpha-(1-4)$. As ciclodextrinas têm uma estrutura tronco-cônica, tal como se pode ver na Figura 5. Como conseqüência da conformação do $\mathrm{C}_{1}$ das unidades de glicose (em forma de cadeira), os grupos hidroxila secundários (ligados a $\mathrm{C}_{2}$ e $\mathrm{C}_{3}$ das unidades de glicose) estão localizados no topo do lado mais largo da estrutura, enquanto que os grupos hidroxila primários (ligados a $\mathrm{C}_{6}$ ) estão posicionados do lado oposto.

Como os grupos hidroxila estão orientados para o exterior da molécula, tornam-na relativamente hidrofílica; por outro lado, a cavidade da molécula apresenta-se hidrofóbica devido ao caráter apolar determinado pelos anéis dos grupos C- $\mathrm{H}\left(\mathrm{H}_{3}\right.$ e $\left.\mathrm{H}_{5}\right)$ e pelo anel de átomos de oxigênio incluídos nas ligações glicosídicas (O4-O4') (Veiga, 1996). Assim, resultam moléculas de superfície exterior polar e uma cavidade apolar. Devido ao caráter hidrofílico da superfície exterior, as ciclodextrinas são solúveis na água, ao mesmo tempo que disponibilizam uma cavidade apolar capaz de formar complexos de inclusão com vários tipos de moléculas hóspede; ou seja, em solução aquosa, a cavidade apolar das ciclodextrinas contém moléculas de água que se organizam num agregado. Estas moléculas podem ser facilmente substituídas por outras, que sejam menos polares e possuam o tamanho adequado para se adaptarem ao interior das ciclodextrinas.

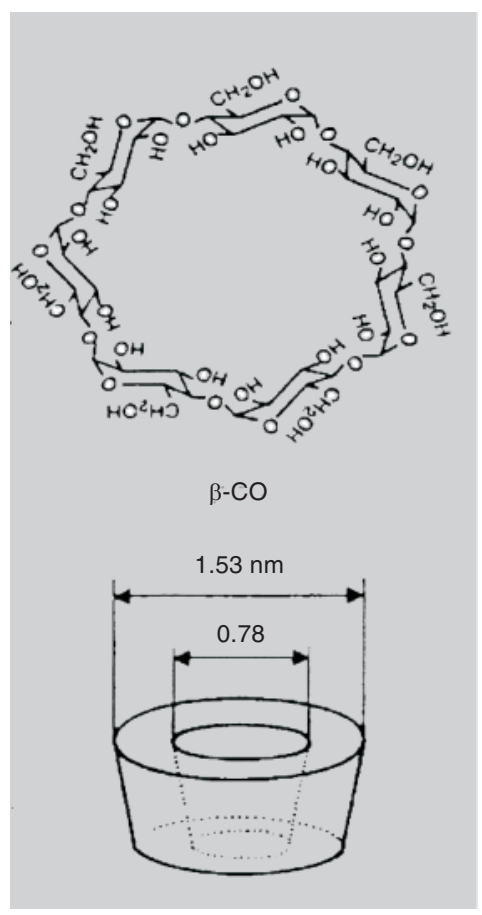

FIGURA 5 - Estrutura da $\beta$-ciclodextrina e suas dimensões moleculares.

As ciclodextrinas atuam, então, como moléculas hospedeiras (Veiga, 1996).

\section{Derivados das ciclodextrinas}

Recentemente, várias espécies de derivados de ciclodextrinas têm sido preparados com o objetivo de expandir as suas propriedades físico-químicas e capacidade de formação de complexos de inclusão.

Em geral, os derivados das ciclodextrinas podem ser divididos em 3 grupos: hidrofílicos, hidrofóbicos e ionizáveis. Os derivados hidrofílicos incluem as ciclodextrinas metiladas tais como 2,6 -dimetil- $\beta$ ciclodextrina (DM- $\beta$-CD) e 2,3,6-trimetil- $\beta$-ciclodextrina (TM- $\beta$-CD), hidroxi-alquiladas, tais como 2-hidroxipropil$\beta$-ciclodextrina (HP- $\beta$-CD) e ciclodextrinas ramificadas tais como maltosil- $\beta$-ciclodextrina $\left(\mathrm{G}_{2}-\beta-\mathrm{CD}\right)$, que podem aumentar a solubilidade aquosa e a velocidade de dissolução de fármacos pouco solúveis na água. Os derivados hidrofóbicos incluem as ciclodextrinas etiladas tais como a 2,6 -detil- $\beta$-ciclodextrina (DE- $\beta$-CD), que pode retardar a velocidade de dissolução de fármacos solúveis em água. Os derivados ionizáveis incluem $O$-carboximetil- $\beta$ ciclodextrina (CM- $\beta$-CD), $O$-carboximetil- $O$-etil- $\beta$ ciclodextrina (CME- $\beta-C D)$, sulfato $\beta$-ciclodextrina e sulfobutileter de $\beta$-ciclodextrina (SBE- $\beta$-CD), que podem 
realizar aumento da capacidade de inclusão, modificações na velocidade de dissolução de fármaco e aliviar o efeito irritante local de alguns fármacos, enquanto que os hidrofóbicos podem modular a liberação de fármaco dos veículos (Matsuda, Arima, 1999).

\section{Formação de complexos de inclusão}

Moléculas ou grupos funcionais de moléculas com dimensões adaptáveis à cavidade das ciclodextrinas e que sejam menos hidrofílicas que a água podem ser incluídas nas ciclodextrinas.

Em solução aquosa, a cavidade ligeiramente apolar das ciclodextrinas é ocupada por moléculas de água, que se encontram em ambiente energicamente desfavorável, o que favorece a substituição das moléculas de água por moléculas hóspede (Figura 6) que sejam menos polares (Veiga, 1996).

Esta complexação das ciclodextrinas com o fármaco vai alterar algumas das suas propriedades físico-químicas (tais como solubilidade e estabilidade), no entanto, a capacidade intrínseca do fármaco de permear as membranas biológicas lipofílicas e de interagir com receptores no organismo não é afetada (Loftsson, 1998a). De fato, durante a formação do complexo, não se formam nem se rompem ligações covalentes (Loftsson et al., 1994b).

Por diversas razões incluindo custos, produção, capacidade e toxicologia, a quantidade de ciclodextrina que pode ser incorporada numa formulação é limitada. É, então, necessário desenvolver métodos que aumentem a eficiência de complexação fármaco-ciclodextrina, tais como, adição de polímeros e outros agentes reológicos, ajustes de $\mathrm{pH}$, entre outros. A eficiência de complexação é igual à solubilidade intrínseca do fármaco $\left(\mathrm{s}_{\mathrm{o}}\right)$ multiplicada pela constante de estabilidade aparente $\left(\mathrm{K}_{\mathrm{c}}\right)$ do complexo fármaco-ciclodextrina. Assim, a eficiência de complexação pode ser aumentada, por incremento de $\mathrm{s}_{\mathrm{o}}$ ou $\mathrm{K}_{\mathrm{c}}$, ou então os dois em simultâneo, tal como está representado na Figura 7 (Loftsson et al., 1999).

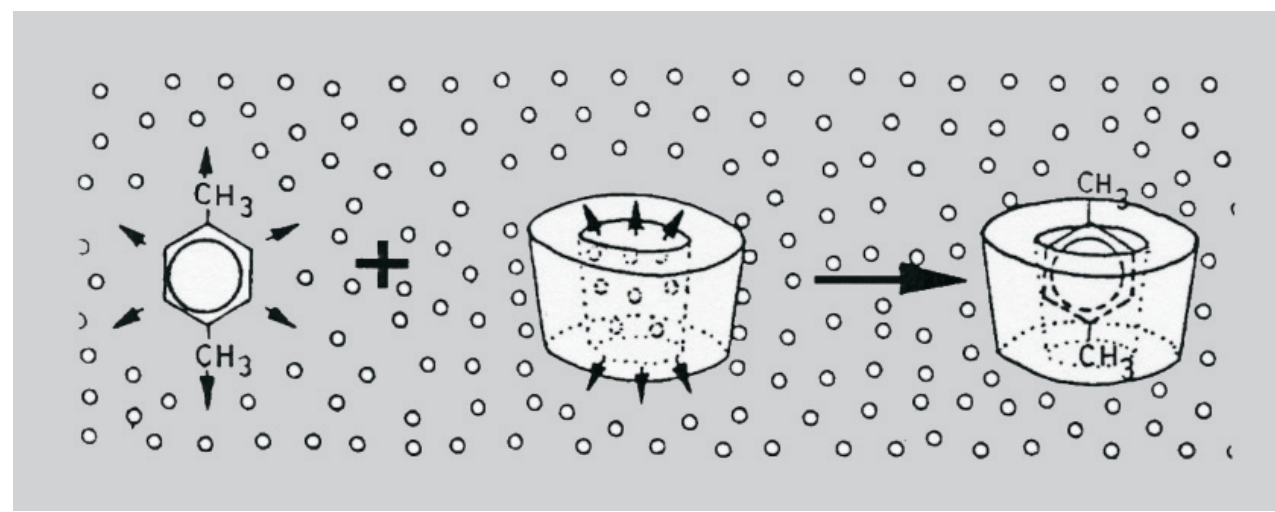

FIGURA 6 - Representação esquemática da formação de um complexo de inclusão com ciclodextrinas. O $p$-xileno é a molécula hóspede; os pequenos círculos representam as moléculas de água.

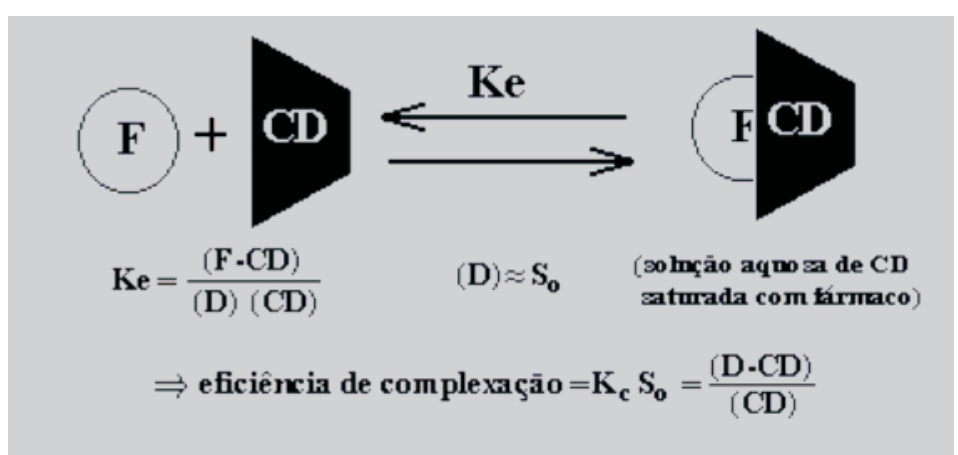

FIGURA 7 - F: molécula de fármaco; CD: ciclodextrina; F-CD: complexo 1:1 de fármaco/ciclodextrina [F]: concentração de fármaco; $[\mathrm{CD}]$ : concentração de ciclodextrina; [F-CD]: concentração do complexo fármaco/ciclodextrina; $\mathrm{S}_{\mathrm{o}}$ : solubilidade do fármaco; $\mathrm{K}_{\mathrm{C}}$ : constante de estabilidade do complexo. Em soluções aquosas de ciclodextrinas saturadas com fármaco a concentração de fármaco livre é aproximadamente igual à solubilidade do fármaco. 


\section{Ciclodextrinas no desenvolvimento de sistemas de liberação transdérmica}

As ciclodextrinas têm sido utilizadas para otimizar a liberação transdérmica de fármacos, por via local ou sistêmica.

Exemplos representativos de ciclodextrinas e seus derivados utilizados em transdérmicos estão apresentados nas Tabelas I e II.

Assim, as ciclodextrinas e seus derivados hidrofílicos aumentam a solubilidade e estabilidade de fármacos em preparações dérmicas tais como soluções aquosas e emulsões. Além disso, as ciclodextrinas e especialmente os seus derivados hidrofóbicos, podem modificar a permeabilidade dos fármacos através da pele, a bioconversão de fármacos nos tecidos alvo e a irritação tópica causada por alguns fármacos.

\section{Estabilização de fármacos em transdérmicos}

As ciclodextrinas são conhecidas por acelerarem e desacelerarem vários tipos de reações tais como hidrólise, oxidação, fotólise, desidratação e isomerização, dependendo das caraterísticas dos complexos de inclusão que se formam nas soluções aquosas e tampões.

Existem muitos trabalhos tendo em vista os efeitos desaceleradores das ciclodextrinas na degradação de fármacos em preparações tópicas. É o caso da b-CD e o complexo formado com o tixortol 17-butirato-21propionato, um dermocorticóide, que mantém a sua estabilidade quando incluído em preparação contendo vaselina e em emulsão óleo em água após 30 dias de armazenamento a $40{ }^{\circ} \mathrm{C}$ (Mastuda, Arima, 1999).

São obtidos efeitos superiores com os derivados de ciclodextrinas em comparação com as respectivas

TABELA I - Exemplos da Utilização de Ciclodextrinas em Transdérmicos (Matsuda, Arima, 1999)

\begin{tabular}{|c|c|c|c|}
\hline $\mathrm{CDs}$ & Abreviatura & Promoção & Fármaco \\
\hline$\alpha$-Ciclodextrina & $\alpha-C D$ & Liberação e/ou permeação & Miconazol \\
\hline \multirow[t]{16}{*}{$\beta$-Ciclodextrina } & \multirow[t]{16}{*}{$\beta-C D$} & Estabilidade & $\begin{array}{l}\text { Tixoxortol 17-butirato } \\
\text { 21-propionato }\end{array}$ \\
\hline & & \multirow{14}{*}{ Liberação e/ou permeação } & Betametasona \\
\hline & & & Ácido 4-bifenilacético \\
\hline & & & Cloranfenicol \\
\hline & & & Ciprofloxacino \\
\hline & & & Acetato de etil 4-bifenilil \\
\hline & & & Flurbiprofeno \\
\hline & & & Hidrocortisona \\
\hline & & & Indometacina \\
\hline & & & Nitroglicerina \\
\hline & & & Norfloxacino \\
\hline & & & Piroxicam \\
\hline & & & Prednisolona \\
\hline & & & Prostaglandina $\mathrm{E}_{1}$ \\
\hline & & & Ácido sulfanílico \\
\hline & & Irritação local & $\begin{array}{l}\text { Cloreto de cloropromazina } \\
\text { Tretinoína }\end{array}$ \\
\hline \multirow[t]{4}{*}{$\gamma$-Ciclodextrina } & \multirow[t]{4}{*}{$\gamma-\mathrm{CD}$} & \multirow[t]{4}{*}{ Liberação e/ou permeação } & Dipropionato de beclometazona \\
\hline & & & Betametasona \\
\hline & & & Menadiona \\
\hline & & & Prednisolona \\
\hline
\end{tabular}


TABELA II - Exemplos de Utilização de Derivados de Ciclodextrinas em Transdérmicos (Matsuda, Arima, 1999)

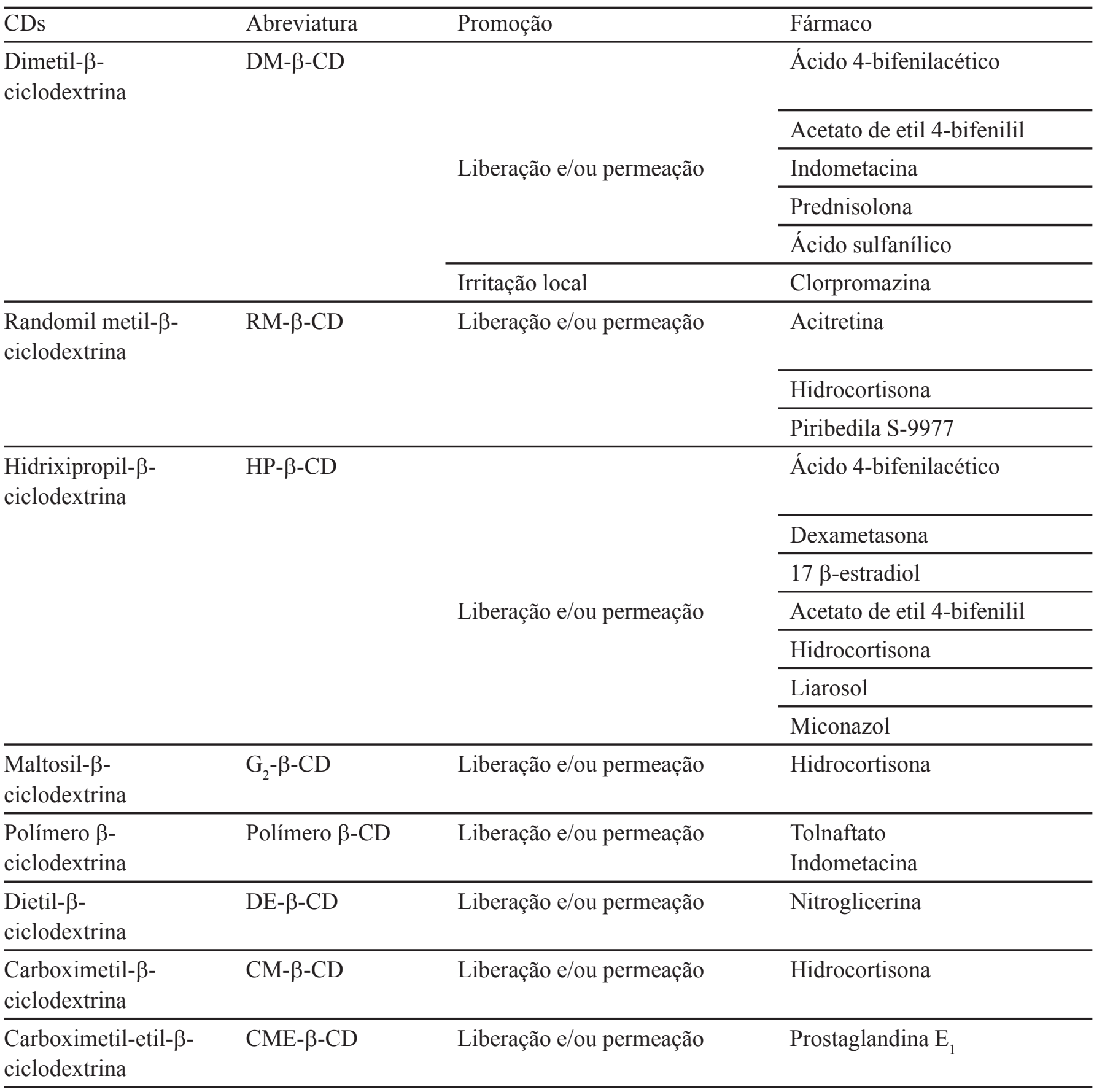

ciclodextrinas naturais. A CME- $\beta-C D$ estabiliza marcadamente a prostaglandina $\mathrm{E}_{1}\left(\mathrm{PGE}_{1}\right)$ num creme contendo álcool graxo e propilenoglicol e em solução aquosa, apesar da ciclodextrina natural que originou este derivado acelerar a degradação em soluções neutras e alcalinas. O efeito de estabilização desencadeado pela CME- $\beta$-CD parece advir de ajustes de $\mathrm{pH}$ para aproximadamente 4 , no qual a $\mathrm{PGE}_{1}$ é mais estável; baixa higroscopia da CME- $\beta$ $\mathrm{CD}$, prevenindo o acesso de moléculas de água à $\mathrm{PGE}_{1}$, e da inclusão de um local reativo da $\mathrm{PGE}_{1}$ na CME- $\beta$-CD quando da formação do complexo.

A maioria dos fármacos retém a estabilidade não só durante o armazenamento, mas também no local de ação de onde o fármaco vai ser absorvido. 


\section{Melhoramento do comportamento farmacocinético e farmacodinâmico no desenvolvimento de fármacos transdérmicos}

\section{As ciclodextrinas na solubilização de fármacos}

Existem diversos trabalhos que referem que a liberação de fármacos pelo veículo é melhorada com a complexação destes com ciclodextrinas. Os exemplos mais representativos são os corticóides dérmicos e antiinflamatórios não-esteróides. Como exemplo, tem-se o caso da betametasona num creme base hidrofílica, no qual o complexo com a $\beta$-CD aumenta a liberação do fármaco a partir do veículo (Otagiri et al., 1984). Assim, estes resultados sugerem que os efeitos de solubilização das ciclodextrinas estão associados com os das ciclodextrinas na liberação do fármaco pelo veículo. Por isso, é provável que os efeitos promotores de absorção de fármaco na pele pelas ciclodextrinas possam ser atribuídos ao incremento de liberação de fármaco pelo veículo.

Contudo, não é simplesmente uma adição de ciclodextrinas à formulação farmacêutica que irá automaticamente resultar em promoção de permeação do fármaco através da pele. Freqüentemente, surgem trabalhos em que os complexos fármaco-ciclodextrinas resultam num decréscimo da biodisponibilidade do fármaco. É importante usar apenas a quantidade de ciclodextrinas suficiente para solubilizar o fármaco no veículo aquoso. Uma pequena quantidade de ciclodextrinas em excesso resulta em decréscimo da biodisponibilidade ótima do fármaco (Loftsson, 1998b).

Existem ainda artigos que defendem que os diferentes resultados indicam que o tipo de veículo afeta significativamente os efeito promotores das ciclodextrinas na liberação de fármacos. Assim, poder-se-á afirmar que, por exemplo, as ciclodextrinas hidrofílicas podem aumentar significativamente a liberação de corticóides e anti-inflamatórios não-esteróides, apenas quando um veículo hidrofílico é usado, sendo importante referir o tipo de veículo utilizado (Matsuda, Arima, 1999).

$O$ efeito das ciclodextrinas na velocidade de permeação de fármaco através da pele pode ser determinada pela atividade termodinâmica do fármaco no veículo e pelo coeficiente de partição entre a pele e o veículo. $\mathrm{O}$ conceito de atividade termodinâmica representa a tendência que o fármaco tem em "liberar-se" do veículo. Supõe-se que aumento nesta atividade leva a aumento da velocidade de permeação do fármaco através da pele. A atividade termodinâmica é diretamente proporcional à solubilidade do fármaco no veículo e é máxima quando se tem solução saturada.
Os resultados encontrados por Loftsson et al. (1998a) suportam estas hipóteses. Quando a concentração de hidrocortisona foi mantida constante e a concentração de randomil-b-ciclodextrina (RM-b-CD) foi gradualmente aumentada, o fluxo através da pele de ratos sem pêlo foi incrementado até um certo ponto, quando todas as moléculas de hidrocortisona estavam em solução, depois o fluxo começou a decrescer com o incremento de concentração de ciclodextrina. O fluxo máximo foi obtido quando apenas a quantidade suficiente de RM-b-CD foi adicionada para dissolver todo o fármaco no veículo aquoso, tal como está representado na Figura 8.

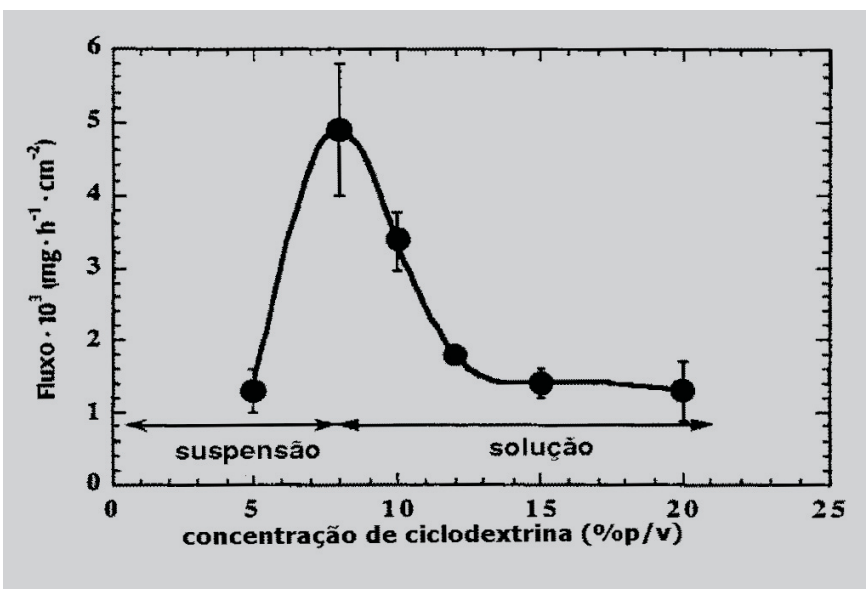

FIGURA 8 - Fluxo de hidrocortisona através da pele de rato sem pêlo. O veículo consiste em 2,3\% (p/v) de hidrocortisona em suspensão ou solução aquosa contendo de 5 a $20 \%(\mathrm{p} / \mathrm{v})$ de RM- $\beta$-CD e $0,25 \%(\mathrm{p} / \mathrm{v})$ de PVP (adaptado de Loftsson et al., 1998a).

Estes resultados estão de acordo com o conceito de atividade termodinâmica em suspensão (Matsuda, Arima, 1999). Apesar da atividade termodinâmica do fármaco em solução ser constante acima da concentração de saturação, concentração de RM- $\beta$-CD acima da concentração ideal faz decrescer a liberação de hidrocortisona. Este fato pode ser explicado pela formação no veículo de maior quantidade de complexo não-absorvível.

As ciclodextrinas promovem a permeação de fármacos lipofílicos, tais como corticóides e antiinflamatórios não-esteróides através da pele, por incremento da atividade termodinâmica do fármaco nos veículos aquosos. No entanto, quantidade adicional de ciclodextrina faz diminuir a velocidade de permeação de fármacos lipofílicos, devido à formação de quantidade adicional de complexos que não são absorvidos. Além disso, deve terse em consideração a possibilidade de outros compostos adicionados em simultâneo poderem afetar os efeitos de 
promoção das ciclodextrinas no desenvolvimento de fármacos transdérmicos.

\section{Ciclodextrinas e polímeros solúveis em água}

Vários autores (Loftsson et al., 1994a; Loftsson et al., 1994c; Loftsson e Olaftsson, 1998d; Loftsson, Siguroardóttir, 1994d; Siguroardóttir, 1994) estudaram o efeito de adição de polímeros à suspensão aquosa contendo corticóide e ciclodextrina, na permeação de fármacos através da pele de comundongos sem pêlo. A adição de pequenas quantidades de polivinilpirrolidona (PVP) e hidroxipropilmetilcelulose (HPMC) à suspensão aquosa contento hidrocortisona-HP- $\beta-C D$ ou dexametasona-HP$\beta$-CD levou a incremento das constantes de estabilidade dos complexos e, conseqüentemente, a aumento da liberação destes fármacos na pele, tal como se pode verificar na Figura 9. Pelo contrário, a adição destes dois polímeros a solução aquosa do fármaco levou à diminuição da velocidade de permeação através da pele. Resultados semelhantes foram obtidos quando foram utilizadas DM- $\beta-C D$, G2- $\beta$-CD e RM- $\beta$-CD (Siguroardóttir et al., 1995).

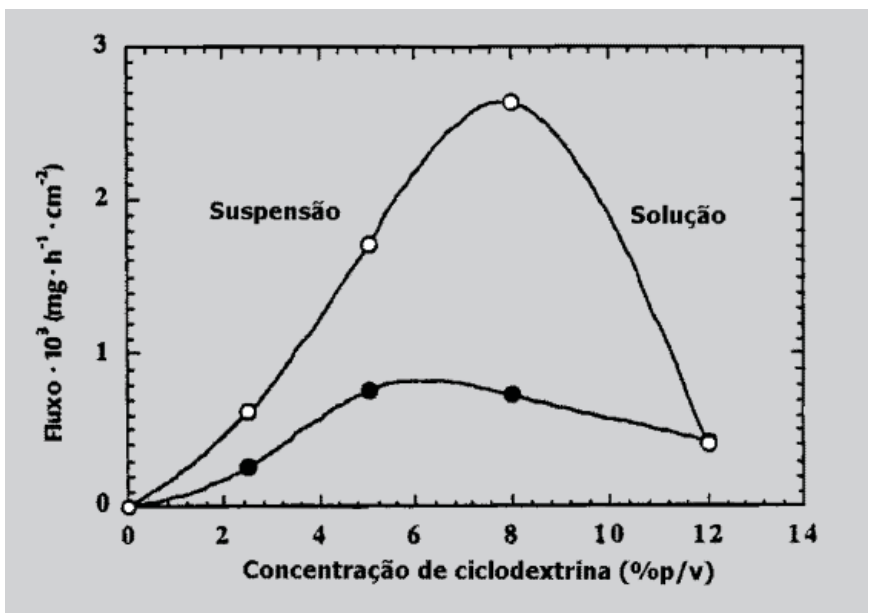

FIGURA 9 - Efeito de $0,25 \%(\mathrm{p} / \mathrm{v})$ de polivinilpirrolidona (PVP) na permeabilidade da hidrocortisona a partir de um veículo aquoso contendo carboximetil- $\beta$-ciclodextrina (CM- $\beta-C D)$ em solução através da pele de rato sem pêlo. A concentração de hidrocortisona foi mantida constante a $1,3 \%(\mathrm{p} / \mathrm{v})$, mas, a concentração de CM- $\beta$-CD foi variada numa amplitude de 0 a $12 \%$ (p/v). Sem polímero: círculos em preto, com polímero $0,25 \%$ (p/v) PVP, círculos em branco (Loftsson, 1998a).

Assim, quando polímeros solúveis em água e ciclodextrinas são utilizados em simultâneo (misturados a $120-140{ }^{\circ} \mathrm{C}$ durante 20 a 40 minutos) obtém-se solubi- lização do fármaco maior do que quando ambos são usados em separado. Este aumento de solubilização é mais do que aditivo, é sinérgico, tal como se pode verificar na tabela III.

Tem sido demonstrado que os polímeros solúveis em água, a baixas concentrações, aumentam a capacidade de complexação da ciclodextrina, aumentando a constante estabilidade do complexo $(\mathrm{Kc})$ fármaco/ciclodextrina e o coeficiente de permeabilidade $(\mathrm{P})$ do fármaco em solução aquosa de ciclodextrina (Tabela IV) através da pele de rato sem pêlo in vitro (Loftsson, 1998a).

\section{Interação com estrato córneo}

As ciclodextrinas podem, também, alterar a permeabilidade dos fármacos através da pele por interação com alguns componentes desta, nomeadamente lipídios. Como exemplo tem-se o S-9977, que é um promotor de permeação que não interage com as ciclodextrinas e aumenta duas vezes a sua ação com a adição de RM- $\beta-C D$ à solução aquosa (Legendre et al., 1995).

O S-9977 é um fármaco novo, com massa molecular de 419,5, solubilidade em água de $5 \mathrm{mg} / \mathrm{mL}$ e estrutura química representada na Figura 10.

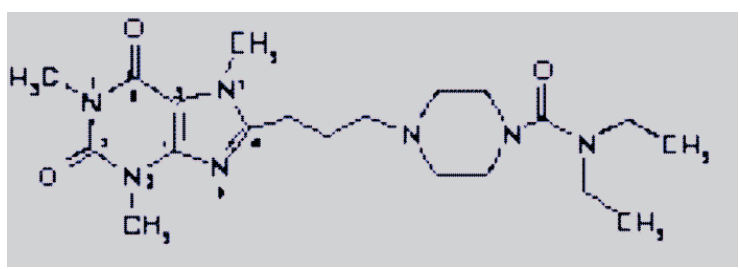

FIGURA 10 - Estrutura química do S-9977.

Loftsson et al. (1989) obtiveram resultados semelhantes referindo que a adição de HP- $\beta-\mathrm{CD} /$ propilenoglicol a $50 \%(\mathrm{p} / \mathrm{p})$ aumenta a liberação dérmica de $17 \mathrm{~b}$ estradiol através da pele de comundongos sem pêlo, em comparação com o propilenoglicol e HP- $\beta-C D 25 \%$ (p/p) em água, pelo que a HP- $\beta$-CD pode aumentar a permeabilidade do estrato córneo como resultado da extração de lipídios, tal como foi descrito por Bentley et al.(1997).

\section{Ciclodextrinas como co-promotores de permeação}

As ciclodextrinas podem, ainda, desempenhar papel de co-promotores em fármacos transdérmicos. Como exemplo, Legendre et al. (1995) verificaram que a combinação entre ácido oléico, um promotor de permeação, e RM- $\beta$-CD aumenta significativamente, para cerca de 30 vezes, o fluxo do cloreto de S-9977, talvez devido a um incremento da difusão do ácido oléico no estrato córneo. 
TABELA III - Efeito da adição de $0,25 \%$ de carboximetilcelulose (CMC) ou $0,25 \%$ de polivinilpirrolidona (PVP) a uma solução aquosa a $10 \%(\mathrm{p} / \mathrm{V})$ de 2-hidroxipropil-b-ciclodextrina (HP-b-CD) na solubilização de alguns fármacos. S: solubilidade em água pura; $\mathrm{S}_{\mathrm{p}}$ : solubilidade numa solução aquosa com $0,25 \%(\mathrm{p} / \mathrm{V})$ de polímero. $\mathrm{S}_{\mathrm{co}}$ : solubilidade numa solução aquosa com $10 \%(\mathrm{p} / \mathrm{V})$ de HP-b-CD; $\mathrm{S}_{\mathrm{cp}}$ : solubilidade numa solução aquosa com $0,25 \%(\mathrm{p} / \mathrm{V})$ de polímero e $10 \%(\mathrm{p} / \mathrm{V})$ de HP-b-CD; $\mathrm{S}_{\mathrm{cp}} / \mathrm{S}_{\text {co: }}$ relação de solubilidades (adaptado de Loftsson, 1998a)

\begin{tabular}{|c|c|c|c|c|c|}
\hline FÁRMACO & $S_{0}(\mathrm{mg} / \mathrm{ml})^{\mathrm{a}}$ & $\mathrm{S}_{\mathrm{p}}(\mathrm{mg} / \mathrm{ml})^{\mathrm{b}}$ & $\mathrm{S}_{\mathrm{co}}(\mathrm{mg} / \mathrm{ml})^{\mathrm{c}}$ & $\mathrm{S}_{\mathrm{cp}}(\mathrm{mg} / \mathrm{ml})^{\mathrm{d}}$ & $\mathrm{S}_{\mathrm{cp}} / \mathrm{S}_{\mathrm{co}}{ }^{\mathrm{e}}$ \\
\hline \multicolumn{6}{|l|}{ CMC } \\
\hline Acetazolamida & 0,70 & 0,84 & 2,52 & 3,11 & 1,23 \\
\hline Alprazolam & 0,07 & 0,18 & 1,28 & 1,55 & 1,21 \\
\hline Carbamazepina & 0,11 & 0,20 & 7,00 & 9,20 & 1,31 \\
\hline Clotrimazol & 0,00 & 0,00 & 1,20 & 1,40 & 1,17 \\
\hline Diazepam & 0,69 & 0,81 & 9,14 & 9,70 & 1,06 \\
\hline Econazol & 0,57 & 0,60 & 5,03 & 7,41 & 1,47 \\
\hline $17 \beta$-Estradiol & 0,01 & 0,17 & 4,78 & 5,35 & 1,12 \\
\hline Etoxizolamida & 0,04 & 0,07 & 1,36 & 1,66 & 1,22 \\
\hline Hidrocortisona & 0,36 & 1,10 & 12,2 & 17,0 & 1,39 \\
\hline Miconazol & 0,04 & 0,06 & 1,98 & 2,50 & 1,26 \\
\hline Oxazepam & 0,03 & 0,04 & 0,90 & 1,42 & 1,57 \\
\hline Prednisolona & 0,38 & 0,53 & 13,6 & 15,3 & 1,13 \\
\hline Progesterona & 0,00 & 0,00 & 4,39 & 6,11 & 1,39 \\
\hline Sulfametoxazol & 0,36 & 0,69 & 10,0 & 12,6 & 1,26 \\
\hline Temazepam & 0,60 & 0,65 & 3,01 & 3,48 & 1,16 \\
\hline Acetonida de triancinolona & 0,03 & 0,07 & 1,84 & 2,58 & 1,40 \\
\hline \multicolumn{6}{|l|}{$\overline{\text { PVP }}$} \\
\hline$\overline{\text { Acetazolamida }}$ & 0,70 & 1,05 & 2,52 & 3,92 & 1,56 \\
\hline Carbamazepina & 0,11 & 0,31 & 7,00 & 8,50 & 1,21 \\
\hline Clotrimazol & 0,00 & 0,00 & 1,20 & 1,80 & 1,50 \\
\hline Econazol & 0,57 & 0,64 & 5,03 & 5,65 & 1,12 \\
\hline Etoxizolamida & 0,04 & 0,06 & 1,36 & 2,72 & 2,00 \\
\hline Oxazepam & 0,03 & 0,04 & 0,90 & 1,14 & 1,27 \\
\hline Progesterona & 0,00 & 0,00 & 4,39 & 5,71 & 1,30 \\
\hline Sulfametoxazol & 0,36 & 0,86 & 10,0 & 14,8 & 1,48 \\
\hline Trimetoprima & 0,82 & 1,35 & 2,83 & 6,47 & 2,29 \\
\hline
\end{tabular}

${ }^{a}$ solubilidade em água pura; ${ }^{b}$ solubilidade em solução aquosa de polímero a $0,25 \%(\mathrm{p} / \mathrm{v})$; ${ }^{\mathrm{c}}$ solubilidade numa solução aquosa de $\mathrm{CD}$ a $10 \%$ (p/V); ${ }^{\text {d}}$ solubilidade em solução aquosa contendo polímero a $0,25 \%$ (p/V) e CD a $10 \%$ (p/V); ${ }^{\text {razão }}$ de solubilidades.

TABELA IV - Efeito da adição de $0,25 \%$ (p/V) de polivinilpirrolidona (PVP) e aquecimento a 120 - $140{ }^{\circ} \mathrm{C}$ durante 20 a 40 minutos na constante de estabilidade aparente $\left(\mathrm{K}_{\mathrm{c}}\right)$ de um complexo 1:1 de hidrocortisona/ciclodextrina e no coeficiente de permeabilidade $(\mathrm{P})$ da hidrocortisona através da pele de rato sem pêlo (in vitro)

\begin{tabular}{|c|c|c|c|c|c|c|}
\hline \multirow[t]{2}{*}{ Ciclodextrina } & \multicolumn{2}{|l|}{$K_{c}\left(M^{-1}\right)$} & \multicolumn{4}{|c|}{$\operatorname{Px10}\left(0^{5}(\mathrm{~cm} / \mathrm{h})\right.$} \\
\hline & sem PVP & PVP & Razão ${ }^{a}$ & sem PVP & PVP & Razão $^{b}$ \\
\hline HP- $\beta-C D$ & 900 & 1100 & 1,2 & 2,9 & 4,0 & 1,4 \\
\hline$C M-\beta-C D$ & 3200 & 9000 & 2,8 & 8,0 & 24 & 3,0 \\
\hline $\mathrm{RM}-\beta-\mathrm{CD}$ & 1700 & 2000 & 1,2 & 15 & 313 & 2,1 \\
\hline Mal- $\beta-C D$ & 2400 & 2700 & 1,1 & 6,1 & 8,0 & 1,3 \\
\hline
\end{tabular}

${ }^{a}$ a constante de estabilidade numa solução contendo PVP dividida pela constante de estabilidade numa solução de composição igual mas sem PVP; ${ }^{\mathrm{b}}$ a constante de permeabilidade dividida pela constante de permeabilidade quando o polímero não está presente no veículo. 
TABELA V - Efeito da HP- $\beta$-CD e do extrato de monoéter glicerol no fluxo de testosterona a partir de uma emulsão óleo em água através da pele de rato sem pêlo

\begin{tabular}{ccccc}
\hline $\begin{array}{c}\text { Concentração HP- } \beta-C D \\
(\% \mathbf{p} / \mathbf{v})\end{array}$ & Sem extrato & & $\mathbf{0 , 5 \%}(\mathbf{p} / \mathbf{V})$ & Extrato na emulsão \\
& $\begin{array}{c}\text { Fluxo } \pm \text { erro } \\
\left(\mu \mathrm{g} \cdot \mathrm{cm}^{-2} \cdot \mathrm{h}^{-1}\right)\end{array}$ & Relação & $\begin{array}{c}\text { Fluxo } \pm \text { erro } \\
\left(\mu \mathrm{g} . \mathrm{cm}^{-2} \cdot \mathrm{h}^{-1}\right)\end{array}$ & Relação \\
\hline Sem HP- $\beta-C D$ & $1,43 \pm 0,08$ & 1,0 & $2,03 \pm 0,15$ & 1,0 \\
$5 \%$ HP- $\beta-C D$ & $2,36 \pm 0,25$ & 1,7 & $2,66 \pm 0,44$ & 1,3 \\
\hline
\end{tabular}

\pm desvio padrão da média (Fluxo \pm erro ). Todas as fases dadoras continham $0.5 \% \mathrm{p} / \mathrm{v}$ de testosterona em suspensão ou solução.

Assim, a combinação de ciclodextrinas e promotores de permeação pode ser muito útil no desenvolvimento de fármacos hidrofílicos por via transdérmica (Matsuda, Arima, 1999).

Loftsson et al. $(1995,1998 b, 1998 \mathrm{c})$ verificaram os efeitos em simultâneo da HP- $\beta-\mathrm{CD}$ e do extrato de monoéter glicerol, um promotor de permeação "convencional", no fluxo de testosterona de uma emulsão óleo em água através da pele de rato sem pêlo, tal como está representado na Tabela V.

Cerca de $60 \%$ de aumento do fluxo foi observado quando $5 \%$ de HP- $\beta$-CD foram adicionados a uma emulsão, $40 \%$ de aumento quando $0,5 \%$ de extrato foi adicionado à emulsão, mas $80 \%$ de aumento do fluxo quando ambos HP- $\beta-C D$ e extrato foram adicionados à emulsão. Assim, a máxima promoção de permeação foi observada quando a HP- $\beta$-CD e extrato foram incluídos no veículo aquoso, simultaneamente.

O promotor de permeação "convencional" (que aumenta a permeação de fármaco por redução da função barreira da pele) e a CD operando por diferentes mecanismos promovem o aumento de permeabilidade máxima.

\section{Mecanismo de liberação do fármaco pelo complexo na pele}

As ciclodextrinas são moléculas relativamente grandes (com massa molecular de 1000 até $1500 \mathrm{Da}$ ) pelo que, em condições normais, permeam as membranas biológicas com considerável dificuldade (Loftsson et al., 1998b).

Sugere-se que as ciclodextrinas atuem como transportadores, captando as moléculas de fármaco hidrofóbico em solução e distribuindo-os à superfície das membranas biológicas, como a pele, mucosas ou córnea, onde o fármaco é partilhado com a membrana. A membrana relativamente lipofílica tem baixa afinidade pelas moléculas de ciclodextrinas hidrofílicas. Por esta razão, elas permanecem na fase hidrofílica da membrana, isto é, no veículo aquoso (creme óleo/água ou hidrogel) (Loftsson, 1998a).

Assim, ciclodextrinas hidrofilicas e os seus complexos dificilmente são absorvidos através da pele, isto é, apenas a fração livre de fármaco vai sendo absorvida. Existe equilíbrio dinâmico entre o fármaco ligado e o fármaco em solução, tal como está esquematizado na Figura 11 .

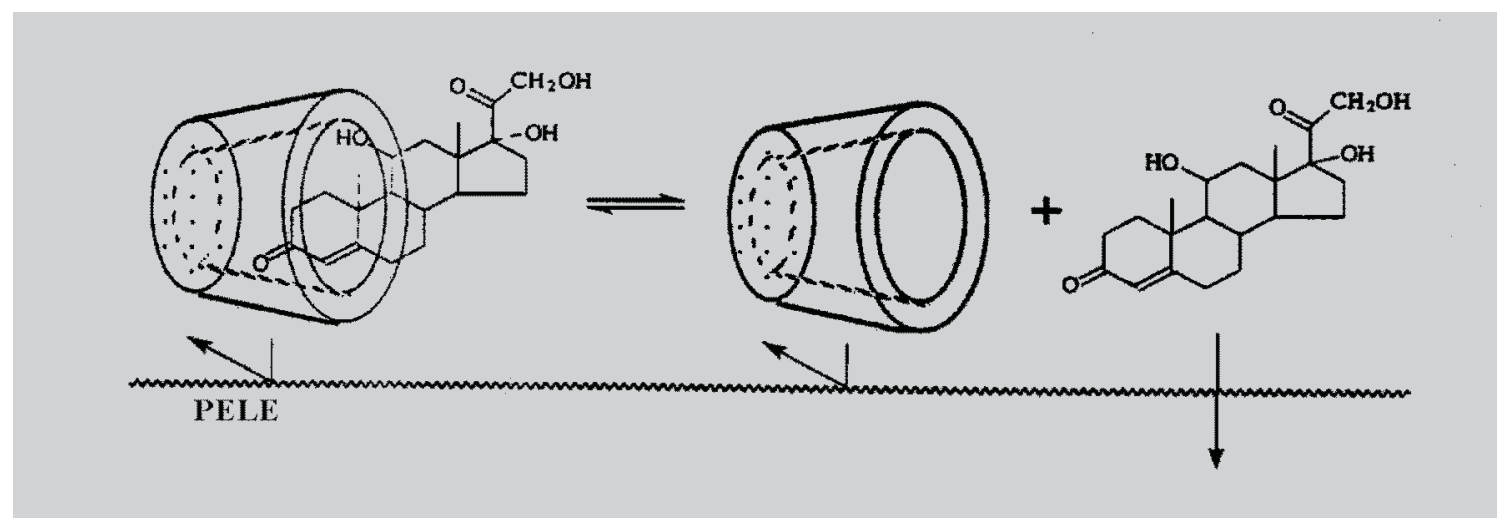

FIGURA 11 - Permeação da hidrocortisona através da pele a partir de um veículo aquoso de ciclodextrina (adaptado de Loftsson et al., 1998e). 
Redução da irritação local no desenvolvimento de transdérmicos

As ciclodextrinas podem diminuir a irritação dérmica causada pelo fármaco, uma vez que na sua presença, apenas uma parte do fármaco se encontra livre, devido ao equilíbrio existente entre este e a sua forma ligada à ciclodextrina (Figura 11). Contudo, os investigadores que defendem que as ciclodextrinas interagem com o estrato córneo (fosfolipídios, colesterol e proteínas) e, conseqüentemente, alteram a sua função barreira, referem-se à possibilidade de estas causarem irritação cutânea, principalmente quando usadas em concentrações elevadas.

\section{PERSPECTIVAS FUTURAS}

Nas ultimas décadas, tem havido grande crescimento na aplicação de técnicas biofísicas sofisticadas para monitorizar a permeação através da pele. A compreensão dos mecanismos de absorção e de promoção de absorção tem avançado e diferentes mecanismos a nível molecular têm sido esclarecidos. Estes conhecimentos poderão ser utilizados no design de novas terapêuticas dérmicas e transdérmicas associadas a promotores de permeação. Deste modo, será possível atingir biodisponibilidade comparável à que se obtém, em regra, por via oral. Com esta possibilidade o desenvolvimento de sistemas de liberação através da pele será mais seguro e eficaz.

As ciclodextrinas constituem grupo de excipientes que têm papel de grande importância em formulação farmacêutica. A compreensão do seu papel como excipientes de fármacos transdérmicos ainda requer alguns estudos que tenham como objetivos compreender melhor os mecanismos que regem a sua ação como promotores de permeação da absorção dérmica e otimizar o desempenho a este nível.

\section{ABSTRACT}

\section{Permeation enhancers in transdermal drug delivery systems: a new application of cyclodextrins}

The present work is a short revision about transdermal permeation enhancers, their mechanism of action including some examples. Routes of permeation across the skin and transdermal delivery are also described. We focus cyclodextrins and their derivatives, structure, chemical properties, formation of inclusion complexes and their action as excipients in transdermal drug delivery systems.
Cyclodextrins are a very important group of excipients used in pharmaceutical technology. One of the most extraordinary properties of cyclodextrins is their ability to increase transdermal drug delivery without affecting the barrier function of the skin.

UNITERMS: Cyclodextrins. Permeation enhancers. Transdermal delivery.

\section{REFERÊNCIAS BIBLIOGRÁFICAS}

ADACHI, H., IRIE, T., UEKAMA, K., MARAKO, T., TANO, T., SAITA, M. Combination effects of Ocarboximetil-O-etil-b-cyclodextrin and penetration enhancer. Eur. J. Pharm. Sci., New York, v.1, p. 177, 1993.

BABAR, A., CHICKHALE, P. J., PLAKOGIANNIS, F. M. Assessment of triethanolamine salicylate release from the dermatological base and the commercial products. Pharm. Acta. Helv., Zurich, v.66, p. 322-328, 1991.

BACH, M., LIPPOLD, B. C. Percutaneous penetration enhancenent and its quantification. Eur. J. Pharm. Biopharm., Amsterdam, v.46, p. 1-13, 1998.

BARRY, B. W. EDWARDS, H. G. M., WILLIAMS, A. C. FTIR and Infra red vibrational study of human skinassignment of spectral bands. J. Raman Spect., New York, v.23, p. 641-645, 1992.

BARRY, B. W. Mode of action of penetration enhancers in human skin. J. Control. Rel., Amsterdam, v.6, p. 85-97, 1987.

BENTLEY, M. V., VIANNA, R. F., WILSON, S., COLLETT, J. Characterization of the influence of some cyclodextrin on the stratum corneum from hairless mouse. J. Pharm. Pharmacol., London, v.49, p. 397-402, 1997.

BODDÉ, H., KRUITHOF, M., BRUSSEE, J., KOERTEN, H. Visualisation small-angle X-ray scattering. J. Invest. Dermatol., New York, v.97, 1991.

BOMMANNAN, D., POTTS, R. O., GUY, R. H. Examination of the effect of ethanol on human stratum corneum in vivo using infrared spectroscopy. J. Control. Rel., Amsterdam, v.16, p. 299-304, 1991. 
BONINA, F. P., MONTENEGRO, L., CAPRARIS, P., BOUSQUET, E., TIRENDI, S. 1-Alkilazacycloalkan-2one esters as prodrugs of indomethacin for improved delivery through human skin. Int. J. Pharm. Amsterdam, v.77, p. 21-29, 1991.

BONINA, F. P., MONTENEGRO, L. Penetration enhancer effects on in vitro percutaneous absorption of heparin sodium salt. Int. J. Pharm, Amsterdam, v.82, p. 171-177, 1992.

BOUWSTRA, J. A., PESCHIER, L. J. C., BRUSSEE, J., BODDE, H. E. Effect of N-alkyl-azocycloheptan-2-ones including Azone on the behaviour of stratum corneum. Int. J. Pharm., Amsterdam, v.52, p. 47-54, 1989.

CHATTERJEE, D. J., LI, W. Y., KODA, R. T. Effects of vehicle and penetration enhancers on the in vitro and in vivo percutaneous absorption of methotrexate and edatrexate through hairless mouse skin. Pharm. Res., New York, v.14, p. 1058-1065, 1997.

CHI, S. C., PARK, E. S., KIM, H. Effect of penetration enhancers on flubiprofen permeation through rat skin. Int. J. Pharm., Amsterdam, v.126, p. 267-274, 1995.

CLANCY, M. J., CORISH, J., CORRIGAN, O. I., A comparison of the effects of electrical current and penetration enhancers on the properties of human skin using spectroscopic (FTIR) and calorimetric (DSC) methods. Int. J. Pharm., Amsterdam, v.105, p. 47-56, 1994.

CORNWELL, P. A., BARRY, B. W., BOUWSTRA, J. A., GOORIS, G. S. Modes of action of terpene penetration enhancers in human skin differential scanning calorimetry, small angle X-ray diffraction and enhancer uptake studies. Int. J. Pharm., Amsterdam, v.127, p. 9-26, 1996.

EL-KATTAN, A. F., ASBILL, C. S., KIM, N., MICHINIAK, B. B. The effects of terpene enhancers on the percutaneous permeation of drugs with different lipophilicities. Int. J. Pharm., Amsterdam, v.215, p. 229240, 2001.

FANG, J., FANG, C., HONG, C., CHEN, H., LIN, T. Capsaicin and nonivamide as novel skin permeation enhancers for indomethacin. Eur. J. Pharm. Sci., Amsterdam, v. 12, p. 196-203, 2001.
FLYNN, G. L. Topical drug absorption and topical pharmaceutical systems. In: BANKER, G. S., RHODES, C. T., eds. Modern pharmaceutics. New York: Marcel Dekker, 1990. p. 263-325.

GARRISON, M. D., DOH, L. M., POTTS, R. O., ABRAHAM, W. Effect of oleic acid on human epidermis: fluorescence spectroscopic investigation. $J$. Control. Rel., Amsterdam, v.31, p. 263-269, 1994.

GAY, C. L., MURPHY, T. M., HADGRAFT, J., KELLAWAY, I. W., EVANS, J. C., ROWLANDS, C. C. An electron spin resonance study of skin penetration enhancers. Int. J. Pharm., Amsterdam, v. 49, p. 39-45, 1989.

GOLDEN, G. M., GUZEK, R. B., HARRIS R. R., MCKIE, J. E., POTTS, R. O. Lipid Thermotropic transitions in human stratum corneum. J. Invest. Derm., New York, v. 86, p. 255-259, 1986.

GUY, R. H., HADGRAFT, J. Physicochemical aspects of percuta-X-ray diffraction study. Int. J. Pharm., Amsterdam, v.84, p. 205-216, 1992.

HADGRAFT, J. Passive enhancement strategies in topical and transdermal drug delivery. Int. J. Pharm., Amsterdam, v.184, p. 1-6, 1999.

IRWIN, W. J., SANDERSON, F. D., LIWAN PO, A. Percutaneous absorption of ibuprofen and naproxen. Effect of enhancer on transport thought rat kin. Int. J. Pharm., Amsterdam, v.66, p. 243-252, 1990.

KAPLUN-FRISCHOFF, Y., TOUITOU, E. Testosterone skin enhancement by menthol though formation of eutectic with drug and interaction with skin lipids. $J$. Pharm. Sci., New York, v.86, p. 1394-1399, 1997.

KIM, D. D., CHIEN, Y. W. Transdermal delivery of dideoxynucleoside-type anti-HIV drugs. 2. The effect of vehicle and enhancer on skin permeation. J. Pharm. Sci., New York, v.85, p. 214-219, 1996.

KITAGAWA, S., LI, H., SATO, S. Skin permeation of parabens in excised guinea pig dorsal skin, its modification by penetration enhancers and their relationship with n-octanol / water partition coefficient. Chem. Pharm. Bull., Tokyo, v.45, p. 1354-1357, 1997. 
KOBAYASHI, D., MATSUZAWA, T., SUGIBAYASHI, K., MORIMOTO, Y., KIMURA, M. Analysis of the combined effect of 1-menthol and ethanol as skin permeation enhancers based on a two-layer skin model. Pharm. Res., New York, v.11, p. 96-103, 1994.

LAMBERT, W. J., KUDLA, R. J., HOLLAND, J. M., CURRY, J. T. A biodegradable tansdermal penetration enhancer based on $\mathrm{N}$-(2-hidroxiethyl)-2-pirrolidone. I. Synthesis and characterization. Int. J. Pharm., Amsterdam, v.95, p. 181-192, 1993.

LEE, C. K., UCHIDA, T., KITAGAWA, K., YAGI, A., KIM, N. S., GOTO, S. Effect of hydrophilic and lipophilic vehicles on skin permeation of tegafur, alclofenac and ibuprofen with or without permeation enhancers. Biol. Pharm. Bull., Tokyo, v.16, p. 1264-1269, 1993.

LEGENDRE, J. Y., RAULT, I., PETIT, A., LUIJTEN, W., DEMUYNCK, I., HORVATH, S., GINOT, Y. M., CUINE, A. Effects of $\beta$-cyclodextrins on the skin: implications for the transdermal delivery of piribedil and novel cognition enhancing-drugs, S-9977. Eur. J. Pharm. Sci., Amsterdam, v. 3, 311-322, 1995.

LOFTSSON T. Increasing the cyclodextrin complexation of drugs and drug biovailability through addition of watersoluble polymers. Pharmazie, Berlin, v.53, p. 733-740, 1998a.

LOFTSSON, T., BODOR, N. Effects of 2-hydroxypropyl-bcyclodextrin on the aqueous solubility of drugs and transdermal delivery of 17 B-estradiol. Acta Pharm. Nord., Stockolm, v.1, p. 185-194, 1989.

LOFTSSON, T., FRIDRIKSDÓTTIR, H., INGVARSDÓTTIR, G., JÓNSDÓTTIR, B., SIGUROARDÓTTIR, A. M. The inflence of 2Hydroxypropyl-b-cyclodextrin on diffusion rates and transdermal delivery of hidrocortisone. Drug Dev. Ind. Pharm., New York, v.20, p. 1699-1708, 1994a.

LOFTSSON, T., FRIDRIKSDÓTTIR, H., SIGUROARDÓTTIR, A. M., UEDA, H. The effect of water-soluble polymers on drug-cyclodextrin complexation. Int. J. Pharm., Amsterdam, v.110, p. 169177, 1994b.
LOFTSSON, T., FRIORIKSDÓTTIR, H., THÓRISDÓTTIR, S., STEFÁNSSON, E. The effect of hydroxypropyl methylcellulose on the release of dexametasone from aqueous 2-hydroxypropyl-bcyclodextrin formulations. Int. J. Pharm., Amsterdam, v.104, p. 181-184, 1994c.

LOFTSSON, T., MÁSSON, M., SIGURDSSON, H. H., MAGNÚSSON, P., GOFFIC, F. Cyclodextrins as coenhancers in dermal and transdermal drug delivery. Pharmazie, Berlin, v.53, p. 137-139, 1998 b.

LOFTSSON, T., MÁSSON, M., SIGURJÓNSDÓTTIR, J. F. Methods to enhance the complexation efficiency of cyclodextrins. S.T.P.- Pharma Sci. Paris, v.9, n.3, p.237242, 1999.

LOFTSSON, T., MÁSSON, M., STEFÁNSSON, E. Cyclodextrins as permeation enhancers. In: Pharmaceutical Technology Conference, 17., Dublin, 1998. Proceedings. Liverpool: Solid Dosage Research Unit, 1998c. v.2, p. 313

LOFTSSON, T., ÓLAFSSON, J. H. Cyclodextrins: new drug delivery systems in dermatology, Int. J. Dermatol., Philadelphia, v.37, p.241-246, 1998e.

LOFTSSON, T., OLAFTSSON, J. H. Cyclodextrins: new drug delivery systems in dermatology. Int. J. Pharm., Amsterdam, v.37, p. 241-246, 1998d.

LOFTSSON, T., SIGUROARDÓTTIR, A. M., ÓLAFSSON, J. H. Improved acitretin delivery through hairless mouse skin by cyclodextrin complexation. Int.J. Pharm., Amsterdam, v.115, p. 255-258, 1995.

LOFTSSON, T., SIGUROARDÓTTIR, A. M. The effect of polyvinylpyrrolidone and hydroxypropyl methylcellulose on hydroxypropyl- $\beta$-cyclodextrin complexation of hydrocortisone and its permeability through hairless mouse skin. Eur. J. Pharm. Sci., Amsterdam, v.2, p. 297-301, 1994d.

MATSUDA, H., ARIMA, H. Cyclodextrins in transdermal and rectal delivery. Adv. Drug Delivery Rev., Amsterdam, v.36, p. 81-99, 1999.

MICHNIAK, B., CHAPMANN, J. M., SEYDA, K. L. Facilitated transport of two model steroids by esters and amide of clofibric acid. J. Pharm. Sci., New York, v.82, p. 214-219, 1993. 
MURA, P., BETTINETTI, G. P., LigUORI, A., BRAMANTI, G. Improvement of clonazepam release from carbopol hidrogel. Pharma Acta Helv., Zurich, v.67, p. 282-288, 1992.

OGISO, T., IWAKI, M., PAKU, T. Effect of various enhancers on transdermal penetration of indometacin and urea and relationship between penetration parameters and enhancement factor. J.Pharm. Sci., New York, v.84 p. 482-488, 1995.

$\mathrm{OH}, \mathrm{H}$., OH, Y., KIM, C. Effects of vehicles and enhancers on transdermal delivery of melatonin. Int. J. Pharm., Amsterdam, v.212, p. 63-71, 2001.

ONGPIPATTANAKUL, B., BURNETTE, R. R., POTTS, R. O., FRANCOEUR, M. L. Evidence that oleic acid exists in a separate phase within stratum corneum lipids. Pharm. Res., New York, v.8, p. 350-354, 1991.

OTAGIRI, M., FUJINAGA, T., SAKAI, A., UEKAMA, K. Effects of a- and b-cyclodextrins on release of betamethasone from ointment bases. Chem. Pharm. Bull. Tokyo, v.32, p. 2401-2405, 1984.

PANCHAGNULA, R., SALVE, P. S., THOMAS, N. S., JAIN, A. K., RAMARAO, P. Transdermal delivery of naloxone: effect of water, propylenoglycol, ethanol and binary combinations on permeations through rat skin. Int . J. Pharm., Amsterdam, v.95, p. 95-105, 2001.

PATIL, S., SINGH, P., SZOLAR-PLATZER, C., MAIBACH, H. Epidermal enzymes as penetration enhancer in transdermal drug delivery. J. Pharm. Sci., New York, v.85, p. 249-252, 1996.

PHILLIPS, C. A., MICHNIAK, B. B. Trandermal delivery of drug with differing lipophilicities using azone analogs a dermal penetration enhancers. J. Pharm. Sci., New York, v.84, p. 1427-1433, 1995.

REDDY, L., H., GHOSH, B. Enhancer aided in vitro permeation of atenolol and prazocin hydrochloride through mice skin. Indian J. Exp. Biol., New Delhi, v.39, p. 47-51, 2001.

SIGUROARDÓTTIR, A. M., LOFTSSON, T. The effect of polyvinylpyrrolidone on cyclodextrin complexation of hydrocortisone through hairless mouse skin. Int. J. Pharm., Amsterdam, v.126, p. 73-78, 1995.
SIGUROARDÓTTIR, A. M. The influence of 2hydroxypropyl- b-cyclodextrin on diffusion rates and transdermal delivery of hydrocortisone. Drug Dev. Ind. Pharm., New York, v.20, p. 1699-1708, 1994.

SINHA, V. R., KAUR, M. P. Permeation Enhancers for Transdermal Drug Delivery. Drug Dev. Ind. Pharm, New York, v.26 n. 11, p. 1131-1140, 2000.

STOTT, P. W., WILLIAMS, A. C., BARRY, B. W. Mechanistic study into the enhanced transdermal permeation of a model b-blockers, propranolol by fatty acids: a melting point depression effect. Int. J. Pharm., Amsterdam, v.219, p. 161-176, 2001.

SUGIBAYASHI, K., NAKAYAMA, S., SEKI, T., HOSOYA, K., MORIMOTO, Y. Mechanism of skin penetration enhancing effect by laurocapram. J. Pharm. Sci., New York, v.81, p. 58-63, 1992.

SUHONEN, T. M., BOUWSTRA J. A., URTTI, A. Chemical enhancement of percutaneous absorption in relation to stratum corneum structural. J. Control. Rel., Amsterdam, v.59, p. 149-161, 1999.

TSAI, J. C., GUY, R. H., THORNFELDT, C. R., GAO, W. N., FEINGOLD, K. R., ELIAS, P. M. Metabolic approaches to enhance transdermal drug delivery. 1. Effect of lipid synthesis inhibitors. J. Pharm. Sci., New York, v.85, p. 643-648, 1996.

TURUNEN, T. M., BUYUKTIMKIM, S., BUYUKTIMKIM, N., URTTI, A., PARONEN, P., RYTTING, J. H. Enhanced delivery of 5-fluorouracil through shed snake kin by two new tansdermal penetration enhancer. Int. J. Pharm., Amsterdam, v.92, p. 89-95, 1993.

TWIST, J. N., ZATZ, J. L. Characterization of solvent enhanced permeation through a skin model membrane. J. Soc. Cosmet. Chem., New York, v.39, p. 324-334, 1988.

VEIGA, F. Complexos de inclusão com ciclodextrinas hidrófilas - Caracterização físico-química e biofarmacêutica. Coimbra, 1996. p. 14-42. [Tese Doutoramento. Departamento de Galénica e Tecnologia Farmacêutica da Faculdade de Farmácia da Universidade de Coimbra]. 
WALTERS, K. A. Penetration enhancers and their use in transdermal therapeutic systems. In: HADGRAFT, J., GUY, R. H., eds. Transdermal drug delivery: Developmental issues and research initiatives. New York: Marcel Dekker, 1989, p. 197-246.

WALTERS, K. A., WALKER, M., OLEJNIK, O. Non-ionic surfactant effects on hairless mouse skin permeability characteristics. J. Pharm. Pharmacol., London, v.40, p. 525-529, 1988.

WILLIAMS, A. C., BARRY, B. W. Urea analogues in propyleneglycol as penetration enhancers in human skin. Int. J. Pharm., Amsterdam, v. 56, p. 43-50, 1989.

WISE, D. L. Handbook of Pharmaceutical Controlled Released Tecnology. New York: Marcel Dekker, 2000. p. 567-617.
XIONG, G. L., QUAN, D., MAIBACH, H. I. Effects of penetration on in vitro percutaneous absorption of low molecular weight human skin. J. Control. Rel., Amsterdam, v.42, p. 289-296, 1996.

YAMANE, M. A., WILLIAMS, A. C., BARRY, B. W. Terpene penetration enhancers in popylenegycol/water co-solvent systems: effectiveness and mechanism of action. J. Pharm. Pharmacol., London, v.47, p. 978-989, 1995.

YOKOMIZO, Y., SAGITANI, H. The effects of phospholipids on the percutaneous penetration of indometacin trough the dorsal skin of guinea pig in vitro. 2. The effect of hydrophobic group in phospholipids and a comparison with general enhancers. J. Control. Rel., Amsterdam, v.42, p. 37-46, 1996.

Recebido para publicação 18 de julho de 2001. 